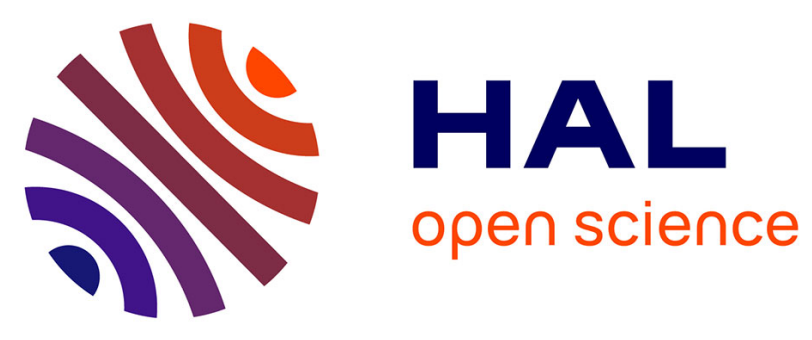

\title{
Extracellular vesicles for personalized medicine: the input of physically triggered production, loading and theranostic properties
}

Max Piffoux, Alba Nicolás-Boluda, Vladmir Mulens-Arias, Sophie Richard, Gabriel Rahmi, Florence Gazeau, Claire Wilhelm, Amanda K A Silva

\section{To cite this version:}

Max Piffoux, Alba Nicolás-Boluda, Vladmir Mulens-Arias, Sophie Richard, Gabriel Rahmi, et al.. Extracellular vesicles for personalized medicine: the input of physically triggered production, loading and theranostic properties. Advanced Drug Delivery Reviews, 2019, 138, pp.247-258. 10.1016/j.addr.2018.12.009 . hal-02408369

\section{HAL Id: hal-02408369 \\ https://cnrs.hal.science/hal-02408369}

Submitted on 13 Dec 2019

HAL is a multi-disciplinary open access archive for the deposit and dissemination of scientific research documents, whether they are published or not. The documents may come from teaching and research institutions in France or abroad, or from public or private research centers.
L'archive ouverte pluridisciplinaire HAL, est destinée au dépôt et à la diffusion de documents scientifiques de niveau recherche, publiés ou non, émanant des établissements d'enseignement et de recherche français ou étrangers, des laboratoires publics ou privés. 
Extracellular vesicles for personalized medicine: the input of physically triggered production, loading and theranostic properties

Max Piffoux ${ }^{l} \dagger$, Alba Nicolás-Boluda ${ }^{1} \dagger$, Vladmir Mulens-Arias $^{l}$, Sophie Richard ${ }^{l}$, Gabriel Rahmi ${ }^{3}$, Florence Gazeau $^{l}$, Claire Wilhelm ${ }^{l}$, Amanda K A Silva ${ }^{l *}$

${ }^{l}$ Laboratoire Matière et Systèmes Complexes, UMR 7057, CNRS, Université Paris Diderot, 10 rue Alice Domon et Léonie Duquet, 75205 Paris cedex 13, France

${ }^{3}$ Gastroenterology and Endoscopy Department, Hôpital Européen Georges Pompidou, Assistance Publique Hôpitaux de Paris, Université Paris Descartes, 20 rue Leblanc, 75015, Paris, France

$†$ These authors contributed equally to this work.

*Corresponding author. Tel.: +33 1 57276203, +33 1 57277101; fax: +33 1 57276211. E-mail address: claire.wilhelm@univ-paris-diderot.fr, amanda.silva@univ-paris-diderot.fr;

\begin{abstract}
Emerging advances in extracellular vesicle (EV) research brings along new promises for tailoring clinical treatments in order to meet specific disease features of each patient in a personalized medicine concept. EVs may act as regenerative effectors conveying endogenous therapeutic factors from parent cells or constitute a bio-camouflaged delivery system for exogenous therapeutic agents. Physical stimulation may be an important tool in the field of EVs for personalized therapy by powering EV production, loading and therapeutic properties. Physically-triggered EV production is inspired by naturally occurring EV release by shear stress in blood vessels. Bioinspired physically-triggered EV production technologies may bring along high yield advantages combined to scalability assets. Physical stimulation may also provide new prospects for highefficient EV loading. Additionally, physically-triggered EV theranostic properties brings new hopes for spatiotemporal controlled therapy combined to tracking. Technological considerations related to EV-based personalized medicine and the input of physical stimulation on EV production, loading and theranostic properties will be overviewed herein.
\end{abstract}


Key-words: Extracellular vesicles, exosomes, microvesicles, physical trigger, personalized medicine, production, loading, theranostics. 


\section{Introduction}

Extracellular vesicles (EVs), including exosomes, microvesicles and apoptotic bodies, are particles at the nanometer range (40-5000 nm size) endogenously secreted by cells in a constitutive or inducible manner [13]. EVs have been found in several body fluids from urine, saliva, plasma, to cerebrospinal fluid. They contain membrane proteins, lipid material as well as other cytoplasmic components. Their composition depends both on their generation pathway and on the physiological state of the cells of origin $[4,5]$. As such, EVs shuttle materials including proteins, lipids, mRNAs and miRNAs, thus constituting a short to long distance form of intercellular communication [6]. After release, EVs can be uptaken by either distal or nearby cells, thereby conveying homotypic or heterotypic transfer of information $[7,8]$.

Formerly regarded as cellular dust [9], EVs are currently considered to be main actors in physiological and pathological processes [10]. EVs act as physiological mediators in coagulation [11], pregnancy [12] and immune response [13] processes. EVs are produced in abundance under pathological conditions such as infection [14] or cancer [15, 16], whereby they sustain and modulate the disease development. Indeed, malignant cells actively secrete EVs during tumor progression that impart molecular signals to healthy counterparts for inducing angiogenesis, immune suppression and tumor growth [17]. In addition to pathological roles, EVs may also display regenerative properties. Indeed, EVs may be behind the paracrine effect of transplanted cells, providing the microenvironment with multiple trophic and survival signals including cytokines to restoring tissue function and homeostasis [18].

Advances in EV research resonate with the current trend of personalized medicine. Personalized medicine aims to tailor clinical treatments in order to meet specific disease features of each patient [19]. In this regard, EVs offer unprecedented perspectives for personalized diagnosis and therapy. Concerning diagnosis, EVs may provide feedback on the treatment effectiveness in real time as a companion diagnostic tool for predicting and monitoring therapy response [20]. As an example, circulating levels of EVs were found to reflect cancer evolution, remission being associated to a reduction on circulating EVs near to healthy levels [21]. Additionally, EVs may provide information on specific parent cancer cell features, such as the mutational status of receptors, to facilitate decisions on therapy choice. For instance, information about the mutation in the epidermal growth factor receptor carried by EVs may be useful for selecting patients who will benefit from 
targeted therapy [22]. EVs investigation may complement the analysis of circulating cancer cells and circulating cancer DNA allowing a rapid snapshot of tumor genome evolution in an approach known as a 'liquid biopsy’ [23]. From a personalized therapy standpoint, one may also foresee the production of EVs from autologous MSCs and their reinjection into the patient in the attempt to revert organ failure. An additional possibility is the engineering of autologous patient EVs with image tracers and therapeutic agents and their reinjection to the patient for an image-guided biocamouflaged drug delivery action.

Physical stimulation may be an important tool in the field of EVs for personalized therapy by powering EV production, loading and therapeutic properties. Physically-triggered EV production is a bioinspired approach, considering naturally occurring EV release by shear stress in blood vessels. Physical stimulation also provides new prospects for high-efficient EV loading. Besides, EV engineering to display responsiveness to physical stimulation opened up a large range of exciting perspectives. Indeed, there is an important need to characterize the fate of EVs and decipher their trafficking in the organism. EV engineering to endow them with contrast properties can contribute to the evaluation of their biodistribution and interaction with recipient cells, unveiling EV roles in both homeostasis- and disease-related mechanisms. From another point of view, EV loading with physically triggered therapeutic agents brings along an interesting opportunity to translate EVs into an actuated bio-mimetic delivery system. Indeed, EVs possess a pleiad of advantages over already existing synthetic counterparts. First, EVs constitute a physiological carrier as they can be autologous, hence, less immunogenic than artificial delivery vehicles. Second, their phospholipid bilayer may potentially fuse with the membrane of recipient cells, thus facilitating the cellular internalization of the encapsulated molecule [24]. Third, their small size and constitution may partially prevent phagocytosis by the mononuclear phagocyte system and enhance their extravasation through blood vessels and their diffusion through tissue as compared with synthetic carriers [25]. Finally, the intrinsic ability to protect their cargo (proteins and/or nucleic acids) from harsh extracellular environment reinforcing their position as promising carriers.

We review herein technology challenges related to the concept EV-based personalized medicine especially focusing on the input of physically-triggered EV production, loading and theranostic properties. First, a brief description of EVs, their pathological and therapeutic roles will be outlined. We will then show an overview on the already existing production and loading methods. In the last place, physically-responsive theranostic EVs will be described before our concluding remarks. 


\section{Classification and biogenesis of EVs}

Extracellular vesicles are membrane delimited sub-cellular entities shed by cells in an evolutionarily conserved manner. The EV classification is a debated question. There are three main subclasses according to the biogenesis: exosomes, microvesicles and apoptotic bodies, whose size varies from 40 to $5000 \mathrm{~nm}$ in diameter. The term exosome was coined in the 1980's by the Johnstone and co-workers whilst studying multivesicular bodies (late endosomes), as these structures shed their interior vesicles content into the extracellular medium [26]. Exosomes were regarded as the final product of the endocytic process, which starts with the fusion of endocytic vesicles and early endosomes. The endocytic content is then processed by degradation, recycling or exocytosis. Upon exocytosis, late endosomes or multivesicular bodies (MVBs) merge with the plasma membrane releasing the intraluminal vesicles (exosomes) into the extracellular environment [27, 28]. Although the composition of EVs is highly variable, common group of proteins can be identified in exosomes originated from different cell types: (i) proteins involved in membrane fusion and transport such as annexin and rab family; (ii) proteins related to cell adhesion, i.e. integrins; (iii) antigen presentation-related proteins such as MHC class I and II ; (iv) cytoskeleton components such as actin and tubulin; (v) enzymes as peroxidases, pyruvate kinases and mainly (vi) tetraspanins, i.e. CD9, CD63, CD81 and CD82 [29].

Biogenically different, microvesicles directly come from direct outward budding and shedding of the cell plasma membrane. Although small microvesicles and large exosomes are in the same size range, the former spans from 50 to $1000 \mathrm{~nm}$ [28]. Microvesicle biogenesis involves phospholipid reorganization and cytoskeletal contraction. The plasma membrane features a natural asymmetric pattern of phospholipids regulated by aminophospholipid-translocases conducting the phospholipid transferring from one plasma membrane leaflet to the other [30]. Upon cell stimulation, due to a significant increase of cytosolic $\mathrm{Ca}^{2+}$, the translocase function is dysregulated leading to the altering of membrane asymmetry, and, ultimately, to the surface exposure of phosphatidylserine (PS). This process leads to microvesicle release following the degradation of the cytoskeleton via $\mathrm{Ca}^{2+}$-dependent proteolysis $[1,28]$. Microvesicles have previously been described to be positive to annexin $\mathrm{V}$, although recent cryo-transmission electron microscopy (cryoTEM) data evidences that only $50 \%$ of vesicles in the plasma are annexin $\mathrm{V}$ positive [31].

Differently from microvesicles and exosomes that are secreted constitutively, apoptotic bodies are released during the programmed death of the cell [28]. These structures are formed during the exclusion phase of 
apoptotic process as the cytoskeleton depolymerizes and causes the membrane to bulge outwards. The emergent bulges segregate from the cell, carrying cytoplasmic content. These are then engulfed by phagocytic cells and their components are recycled. Since apoptotic bodies generally fetch intact organelles as a consequence of the biogenesis [32] , the resulting size ranges from 50-5000 nm, and therefore, often larger than other types of EVs.

Despite the fact that the prevailing EV classification is largely accepted by the scientific community, the differentiation of EVs into these sub-types is still not clear due to the current technical pitfalls and lack of consensus in their characterization. In addition, the different EVs also display common features implying that body fluids encompass a continuum of vesicle types with overlapping characteristics at times [33].

\section{Pathological roles of EVs}

EVs are able to transfer information to other cells and influence their function. EVs exert their effects on biological processes in a pleiotropic manner by interacting with cell surface receptors via proteins and bioactive lipid ligand, by conferring their membrane content to the recipient cell surface or by delivering effector molecules (including oncogenes, transcription factors, small and large non-coding RNAs) into recipient cells $[27,34,35]$. EVs were purified from most body fluids and there are clear evidences that they play an important role in the regulation of physiological processes such as stem cell maintenance [34], tissue regeneration [36], immune surveillance [37] and coagulation [38], but also in pathological processes [27]. EVs can therefore be considered as a signaling platform: multifunctional agents capable of controlling biological functions.

The most investigated pathological role of EVs concern their implication in tumor biology. It has been shown that EVs actively participate in the formation of a pre-metastatic tumor niche [35, 39]. Likewise, EVs stimulate and modulate tumor progression $[35,40]$ via their ability to induce cell proliferation, hence directly triggering tumor growth and angiogenesis. EVs promote metastasis, through protease secretion [41] and the consequent matrix remodeling, as well as immune evasion by modulating $\mathrm{T}$ cell activity [42].

Apart from cancer, EVs also participate in the spreading of a large range of pathogens such as HIV via the horizontal transfer of chemokine receptor 5 (CCR5) [43], Epstein-Barr virus (EBV) that spreads through the transfer of EBV-targeted gene-specific miRNAs in non-infected cells [43], and prions via the delivery of the PrP protein and glycoforms into recipient neuronal cells [44]. Evidence also suggests that EVs contribute, in 
some extent, to the propagation of neurodegenerative diseases as neurons communicate through the secretion of EVs [45]. Neuronal EVs nonetheless are able to provide long-range communication within the central nervous system and have an effect on neuronal networks located at longer distances. In the context of Alzheimer's disease, the amyloid $\beta$ peptides are indeed released associated to exosomes, thus contributing to the deposition of amyloid $\beta$ in neighbor zones of the brain [46]. Besides, the EV circulating levels have been found to be elevated in other diseases including malaria [47], cardiovascular diseases [48], auto-immune diseases such as systemic lupus erythematous [49] and diabetes mellitus [50].

\section{Regenerative role of EVs}

Mesenchymal stem cells (MSCs) are probably one of the most investigated cell types in regenerative medicine, being considered as a remarkable player of the tissue regeneration approaches. Indeed, MSCs display regenerative/immunomodulatory properties, as well as low immunogenicity [51, 52]. One of the main mechanisms involved in MSC-mediated tissue repair concerns cell paracrine effect $[18,53]$. MSCs provide multiple trophic and pro-survival signals including cytokines, which are mainly released by means of EVs. EV-mediated paracrine effect seems to bridge the gap between cell administration and the injection of soluble biological factors, overcoming limitations related to both. On the one side, limitations related to viable cell transplantation could be overcome. This applies to the risks of uncontrolled cell replication, differentiation or vasculature occlusion. On the other side, EV approach also circumvent instability drawbacks associated to manufacture, storage and administration of soluble biological factors since EVs not only carry but also protect its bioactive cargo [18].

The protective and reparative properties of MSC EVs represent an important therapeutic tool for personalized medicine [54]. One may foresee the production of EVs ex vivo, their purification, characterization and reinjection into the patient in the attempt to revert organ failure. In this regard, the regenerative potential of EVs was demonstrated preclinically for several organs such as liver, heart, lungs, brain, kidneys, bones and skin (Figure 1), as it will be overviewed herein.

Several reports highlight the role of MSC EVs in cardiac protection. The regenerative effect of intramyocardial injection or reperfusion of MSC EVs was investigated in murine models of myocardial ischemic injury. EV therapy was observed to decrease the infarct size and improve blood flow as well as cardiac systolic and diastolic performance in comparison with control [55-58]. 
EV-mediated lung repair was equally investigated. Tests were performed in a mice model of acute lung injury induced by Escherichia coli endotoxin. MSC EVs played a therapeutic role by a reduction in pulmonary edema, lung protein permeability and in inflammation [59]. The therapeutic properties of MSC EVs was also shown in a murine model of acute kidney injury. Gatti et al., demonstrated that administration of MSC vesicles induced an inhibition of apoptosis and a stimulation of tubular epithelial cell proliferation [54]. In a related approach, Reis et al., and Zhou et al. demonstrated that EVs from MSCs inhibited necrosis, apoptosis and promoted cell proliferation as well as improvement of renal function in murine models of kidney injury [55, 56].

MSCs EVs may also play a significant role for the treatment of liver fibrosis by inhibiting epithelial-tomesenchymal transition (EMT) and protecting hepatocytes. Indeed, in a murine fibrotic liver model, MSC vesicles decreased the hepatic inflammation and the collagen production while reducing fibrosis by tissue remodeling [57-59].

MSC EVs seem to be also of interest for wound healing by accelerating re-epithelialization and reducing scar widths. In this case, therapy based on MSC EVs may promote collagen production as well as neoangiogenesis. Indeed, MSC EVs induced the generation of new vessels and favored their maturation in wound sites via the stimulation of the proliferation and migration of HUVECs. MSC EVs also facilitated skin wound healing via the recruitment of fibroblasts to tissue wound area. Moreover, MSC EV treatment appeared to engage two kinds of response depending of the stage of the pathology: increase of collagen I and III production in the early stage and inhibition of collagen expression in the later stage to reduce scar formation $[60,61]$. These results highlight the high potential of MSC vesicles for the treatment of cutaneous wounds.

The impact of MSC EVs on bone regeneration was also studied. Furuta and his team have shown that the use of MSC EVs allowed, by a paracrine effect, an acceleration of fracture healing [62]. In a related investigation, it was demonstrated that treatment with MSC EVs enabled to promote osteochondral regeneration. MSC EVs completely restored cartilage and subchondral bone [63].

In the neurosvascular field, MSC vesicles were reported to participate in functional recovery post stroke due to increased axonal density and increased synaptophysin-positive areas in the injured zone. MSC vesicles treatment also resulted in an increase of neuroblasts and endothelial cells inducing an improvement of neurite remodeling, neurogenesis, and angiogenesis [64]. Besides their intrinsic regenerative properties, EVs may be 
customized in order to display further functionalities. For instance, a highly discussed paper in the field reported neuron targeting and crossing of the blood brain barrier by engineering EV-secreting cells to express Lamp2b (an enriched in EV protein) fused to the neuron-targeting RVG peptide. The obtained EVs were used for the neuronal delivery of BACE-1 siRNA, successfully silencing BACE-1, a beta secretase in Alzheimer's disease related to toxic beta amyloid formation and deposition [65].

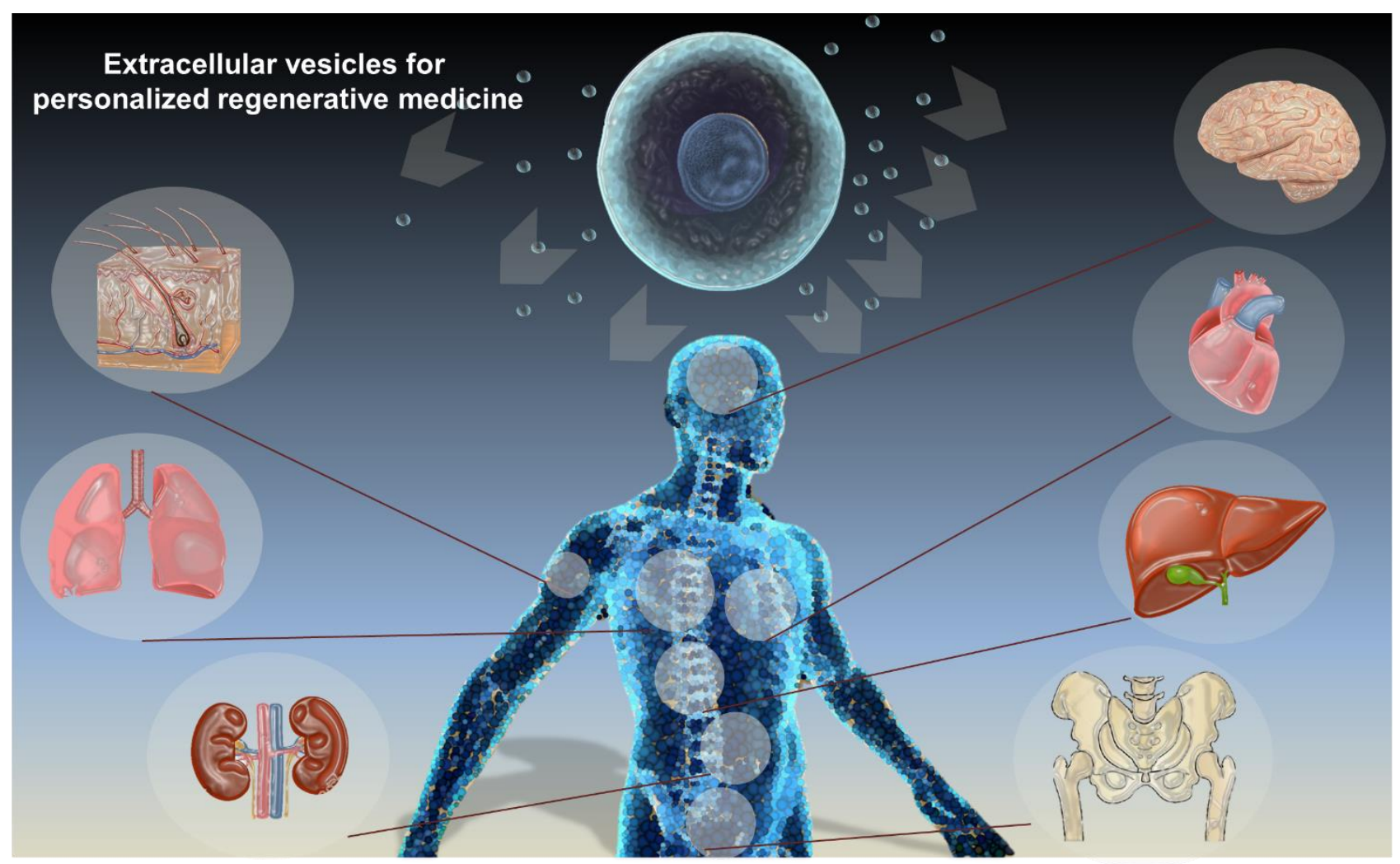

Figure 1: Hopes on the regenerative effect of extracellular vesicles extends to several organs. Considering preclinical data, extracellular vesicles, especially from mesenchymal stem cells, hold great promises for the regeneration of the several organs including heart, lungs, bones, liver, skins and kidneys.

\section{Physically triggered EV release in the organism: physiology, pathology and mechanisms}

EVs are continuously released in blood vessels in response to physiological or pathological shear stress levels (Figure 2). Shear stress in blood vessels is a well-known trigger stimulus for EV release from endothelial as well as blood cells, such as platelets and erythrocytes $[66,67]$. For instance, the basal level of circulating phosphatidylserine-positive EVs from platelets is $10^{7} / \mathrm{ml}$, representing a constitutive release due to platelet aging and shear stress [66]. Shear stress can modulate not only EV release amount but also its constitution. 
Hergenreider et al. evidenced that endothelial cells exposed to physiological arterial shear-stress levels (20 dynes $/ \mathrm{cm}^{2}$ ) released EVs enriched in atheroprotective miR-143/145, when compared with EVs obtained from static endothelial cell controls [68]. The physiological process of EV release may be enhanced by intensive physical exercise $[69,70]$ or by pathological dysfunction such as vessels stenosis [71, 72]. Considering physical exercises, there is an increase in blood pressure, which elevates shear stress in blood vessels and subsequently the level of circulating EVs $[69,70,73]$. Such EVs may participate in distal signaling in exercisemediated processes [73]. Regarding stenosis, the pathological reduction in vessel lumen diameter induces extremely high shear stress levels. While wall shear stress range in normal veins and arteries is 1-10 and 1060 dyne $/ \mathrm{cm}^{2}$, respectively, this value may exceed 1000 dyne $/ \mathrm{cm}^{2}$ in highly stenotic arteries [74]. Wall shear rates may reach $20000 \mathrm{~s}^{-1}$, as the case in stenosed coronary arteries [75]. Patients featuring severe aortic valve stenosis displayed increased circulating EV levels in correlation with valvular shear stress intensities [76]. Procoagulant-rich EVs from platelets, which are abundantly released by shear forces in stenotic vessels may be behind the correlation between stenosis and thrombosis or acute cerebral infarction [77, 78]. Similarly, arterial hypertension, which is related to increased shear stress in blood vessels [79, 80], is also associated to increased circulating levels of endothelial and platelet EVs [81]. Patients with atherosclerotic sites, which are equally related to pathologically high shear stress levels [82], display elevated circulating EV levels as well [83]. Circulating EVs have been currently regarded as a potential marker for cardiovascular diseases whose prognostic value may be of interest to evaluate cardiovascular risk [84]. 


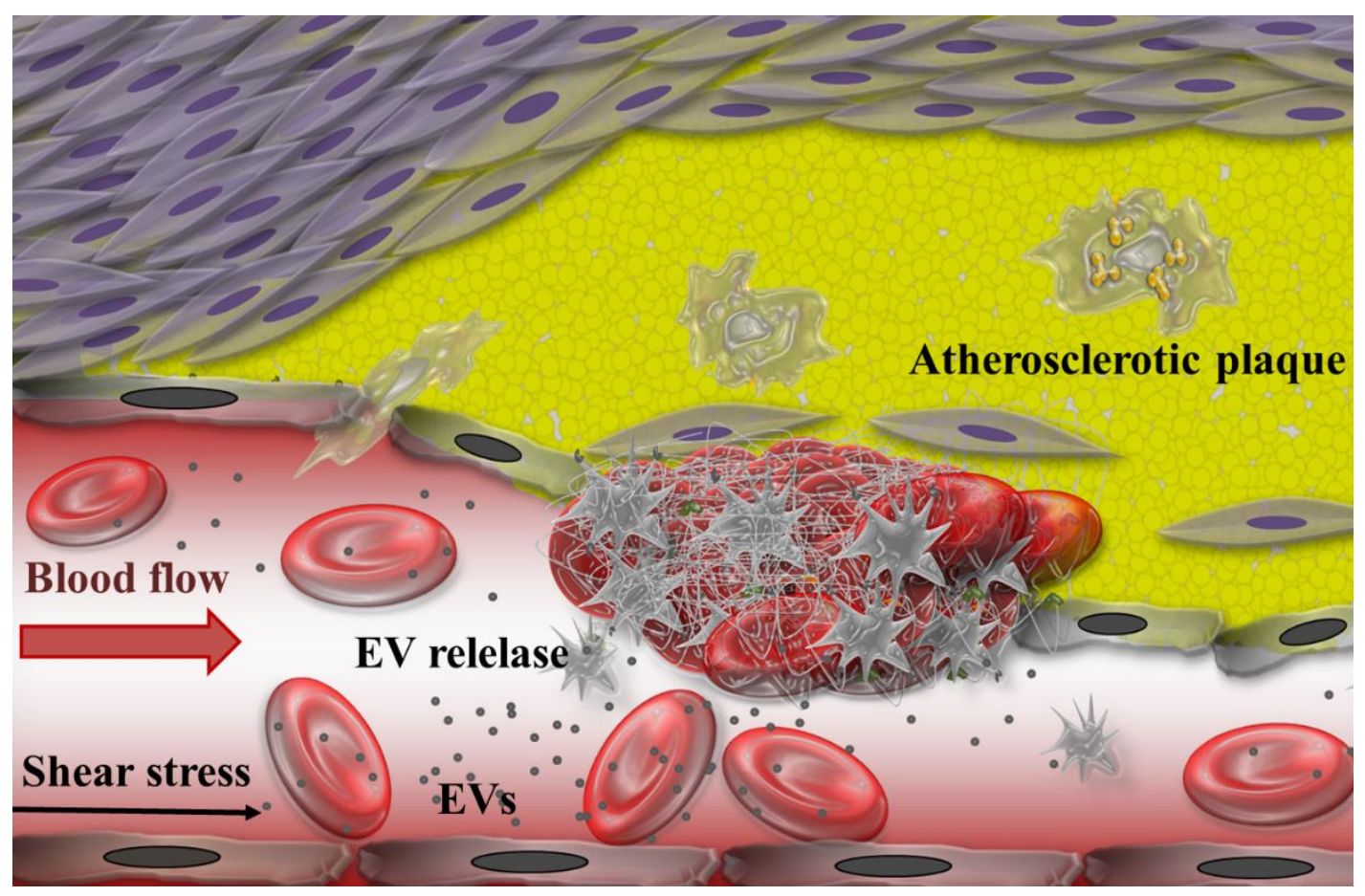

Figure 2: Physically triggered EV release in blood vessels due to physiological and pathological shear stress levels. Increased EV release is observed in sites of high shear stress such as atherosclerotic plaques.

The mechanisms involved in EV release triggered by a shear stress may involve active cell response to membrane tension. Cells respond to membrane tension by regulating their membrane area [85]. In this regard, plasma membrane folds and blebs contribute to enhance membrane surface. Once cell membrane is submitted to a shear stress, these membrane folds and blebs flatten, resulting in an increase in membrane tension. When membrane reservoir is depleted, membrane tension is no more buffered, activating trafficking and exocytosis to restore membrane reservoir [86-89]. Different pathways may activate cell trafficking. For instance, cell spreading-induced membrane tension results in exocytosis activation via a glycosylphosphatidylinositol (GPI)anchored protein recycling pathway together with Golgi lysosome release [90]. Enhanced exocytosis may be related to an increased exosome release.

In the case membrane tension leads to membrane rupture, there is an elevation in intracellular $\mathrm{Ca}^{2+}$ triggering lysosomal exocytosis and fusion of lysosomes with the plasma membrane, mediating resealing [91]. Plasma membrane wounding leads to a local drop in membrane tension and the rapid formation of a localized blebs. An increase in intracellular $\mathrm{Ca}^{2+}$ levels is known to participate in $\mathrm{EV}$ 
release process $[92,93]$. It has been shown that $\mathrm{Ca}^{2+}$ entry coupled to tension drop promote the local recruitment of Endosomal Sorting Complex Required for Transport-III (ESCRT-III) [94]. Recent research has evidenced that ESCRT components participate in the biogenesis of microvesicles during budding step [95] and pinching-off [96].

It is important to highlight, that EV release in response to shear stress is expected to be dependent on shear stress intensity. At higher shear stress levels, the mechanisms involved in EV formation may be quite different. Particularly, when the elongation of plasma membrane reaches a maximum, the cell is no more able to withstand membrane tension. The so-elongated lipid bilayer is thermodynamically unstable, leading to the tearing in fragments that spontaneously self-assembly to form EVs [97].

\section{EV production technology}

EV production technology is a main issue to be addressed to enable EVs application as regenerative effectors or bio-camouflaged delivery systems for drugs and contrast agents. Concerning the latter, both healthy and malignant cells have been investigated as source for EV production. In the case of EVs from malignant parent cells, homotypic cell transfer is envisioned as a Trojan horse approach to deliver a cytotoxic drug to tumor cells [98]. However, the translation of these nanosystems into clinics encounters a major challenge concerning a production method that assures not only high quality but also high quantity. Moreover, the question of the cell source remains unclear. Since EVs might mimic parent cell features, the cell type source may impact targeting and biological properties of EVs.

Since EVs are constitutively released by cells, comparative studies in vitro have been performed to evaluate the relative amount of EVs spontaneously secreted by several cells. These studies concluded that MSC derived from hESC (human embryonic stem cells) secrete the highest amount of exosomes followed by the human embryonic kidney cell line (HEK) [99]. Nonetheless, most of current analysis do not take in consideration that both EV production and release into the medium are dynamic processes limited by cellular uptake recycling. EV production will indeed increase until reaching a plateau depending on cell production rate, cell recapture rate and culture medium volume. In this regard, a time range until plateau of about 8-12 hours was reported for breast cancer cells, for instance [100]. 
When considering spontaneous EV release, it is important to highlight that in vitro culture of most cell lines and primary cells require fetal bovine serum (FBS) or platelet lysate (PL) as a supplement to a basal medium. FBS and PL contain certain nutritional and macromolecule growth factors that enhance cell growth. It has to be noted that the use of FBS and PL contains on their own a lot of EVs, and if not depleted from them, they can be co-purified, obscuring the role of the produced EVs [101, 102].

Currently, the method of choice for scalable EV production relies on spontaneous EV release from cells cultured in hollow-fiber bioreactor providing high surface-to-volume ratios and supporting large numbers of cells at high densities $[103,104]$. The hollow fibers supply anchored cells with the medium in a laminar flow. Although the method concentrates EVs in a reduced volume, the major inconvenient is that the protocol is extremely time consuming resulting in a low-yield EV release of about $5 \mu \mathrm{g}$ from $10^{6}$ cells in 14 days [103]. Besides spontaneous EV release process, cells can be further stimulated by external signals to trigger a larger amount of EV release into the extracellular medium. As such, research performed to date reports the use of mainly two approaches: biological/chemical stimulation and physical methods (Figure 3).

\subsection{Biological/Chemical trigger}

Biological approaches devoted to increase EV production are based on external bioactive stress applied to cells. In this sense, serum deprivation stands out as a widely-used trigger for inducing cell stress in vitro as it reduces basal cellular activity and induces apoptosis. Studies performed by Sun et al., showed that serum deprivation augments EV release by 2.5 -fold in human myeloma cells [105]. Although EV shedding is an energy-dependent process, certain tumor cell lines, such as myeloma cells, have the ability to support intense EV shedding whilst reprogramming their metabolism to fulfill the requirements prompted by nutrient deprivation. Likewise, lung and breast cancer cells can display an increment of EV production when subjected to hypoxia $[106,107]$. Given the role of EVs in tumor progression, the increase in the release of EV by tumor cells under hypoxia could lead to an exacerbated tumor invasion and, ultimately, to metastasis. Serum deprivation and hypoxia are considered as simple EV production methods since no additional procedures are required to eliminate the vesiculation-triggering external agent.

Although opposite, cell activation represents a usual strategy to trigger EV release. Indeed, upon stimulation with TNF- $\alpha$, IL-8, and leukotriene B4, neutrophils double the amount of EV released compared with resting cells [108]. Interestingly, EVs obtained in this context, exhibit a different phenotype as compared to serum 
starvation-induced counterparts. That is the case for endothelial cell-derived EVs that display constitutive markers such as CD31 and CD105 when produced under serum starvation, whilst expressing CD54 and CD62E when activated by TNF- $\alpha$ [4]. However, this method is hindered by the need for further purification steps in order to remove the bioactive agent in excess.

EV secretion can also be triggered by chemical agents. For exemple, cytochalasin B, an actin polymerization inhibitor, promotes the release of EVs featuring cell surface receptors and contain intraluminal proteins from the cytosol $[109,110]$. In fact, cytochalasin B-treated freshly isolated neutrophils show an enhancement of EV release[108]. Ethanol has also been shown to increase EV production by hepatocarcinoma cells (Huh7.5 cells) that release large quantity of EVs in a time- and dose-dependent manner, reaching a 10-fold maximum upon incubation with $100 \mathrm{mM}$ of ethanol [111].

\subsection{Physical trigger}

Recent research has shown that EVs and EV-like cell derived vesicles are triggered by applying physical and mechanical stress on cells. Several groups indeed have tried to exploit this new approach to obtain EVs. For example, a study performed by Jiang et al. demonstrated that high shear-stress induces a significant increase in microvesicle production in megakaryocytes [112]. Our team [113] and others [97] have demonstrated the feasibility of inducing EV release by shear stress in a laminar flow using a microfluidic device. EV release was induced by forcing cells to pass through microchannels inferior to cell diameter in a biomimetic approach, inspired by EV release via high shear stress in blood vessels. The mechanism that governs the shear stressinduced nanovesiculation resides on the pressure-induced elongation of plasma membrane due to the resistance to shear forces. The so-elongated lipid bilayer is not stable thermodynamically, leading eventually to the formation of small nanovesicles [97]. On the other side, Yoon et al. conceived a cell-slicing system to produce nanovesicles directly from cells, exploiting the self-assembly capacity of phospholipids. The system is made up of silicon nitride blades along the microchannels to slice cell membrane when passing through the device. As a result, free plasma membrane fragments with intact lipid bilayer structure form vesicles that contain parental cell-derived factors as well as possible exogenous materials present in the medium [114]. Notably, authors should explore the potential release of organelles during the cell membrane disruption.

Alternatively, the use of centrifugal force combined with filters (10 and $5 \mu \mathrm{m}$ ) is also shown to be a promising tool to obtain nanosized vesicles. While cells are forced to pass through membrane pores by the centrifugal 
speed, cell shape changes. Due to the friction force generated between the plasma membrane and the surface of the filter (hydrophilic surfaces interaction), cell elongates and disrupts. Then, phospholipids are able to spontaneously self-assemble generating vesicles in the $100 \mathrm{~nm}$ size range. The yield is 250 higher than classical spontaneous release, based on protein quantification [115]. A similar approach was used by Jang et al. which subjected cell types to several extrusion steps through filters with decreasing size pore after internalizing a chemotherapeutic drug into cells [116]. Another similar approach investigated is the use of cavitation to disrupt cells followed by ultracentrifugation and sonication to create nanosize vesicles, and loaded with a pH driven gradient with a therapeutic compound [117].

It must nonetheless be kept in mind that these techniques are mainly based on the destruction of cell membrane and the self-assembly of the smaller generated membrane fragments into nano-sized lipid bilayer. The resulting vesicles are most probably constituted by organelles membranes or carry along genetic material, hence may not necessarily share all common features from biogenic EVs. This issue reinforces the need to provide appropriate characterization of mechanically-triggered EVs before considering pre-clinical and clinical implementation.

A related cell-disruption method for producing EV-like entities, known as "nanoghosts", has received increasing attention $[118,119]$. The nanoghosts production is based on the isolation of the whole cell plasmatic membrane after removal of cytosolic fraction by consecutive cell disruption (i.e., nitrogen cavitation, hypotonic shock, and extrusion) and differential centrifugation. The obtained nanoghosts are then devoid of cytosolic proteins and nucleic acids that would otherwise potentially carry further signaling information. Although nanoghosts are not from natural biogenesis, they represent promising candidates as delivery systems due to their (i) biomimetism, (ii) stealthiness, (iii) biocompatibility, (iv) forthright drug loading capacity through mechanical approaches and (v) possibility of bio-engineering via parental cells. Concerning the latter, parent cells may be bio-engineered to express a specific surface protein with therapeutic potential. Nanoghosts can inherit such new factor harnessing researchers with an extremely tunable nanocarrier [120]. Additionally, as cells are not subjected to any external signal that could modulate cell biology (i.e., starvation, cytokines, chemokines, etc.), no putative change is induced in the cytoplasmic membrane as for its protein and lipid composition, and thus, it mimics exactly the intact cellular surface microdomains. MSC plasma membranederived nanoghosts indeed recapitulate the expression of typical membrane receptor such as CD44, CD90, and 
CD105 [121]. Likewise, mouse macrophage membrane-coated liposomes exhibit similar level expression of integrins $\alpha 4$ and $\beta 1$ as compared to murine macrophage RAW264.7, which endows liposomes with avidity against VCAM1-expressing tumor cells [122]. This constitutes a huge advantage over the heterogeneous extracellular vesicles, which greatly differs in terms of membrane composition depending on the triggering signal and the intracellular origin. By keeping virtually unchanged membrane microdomains whose receptor and ligand content mimics that of parental cells, researchers can exploit specific receptor-ligand interaction more accurately to increase tissue-specific homing [123].

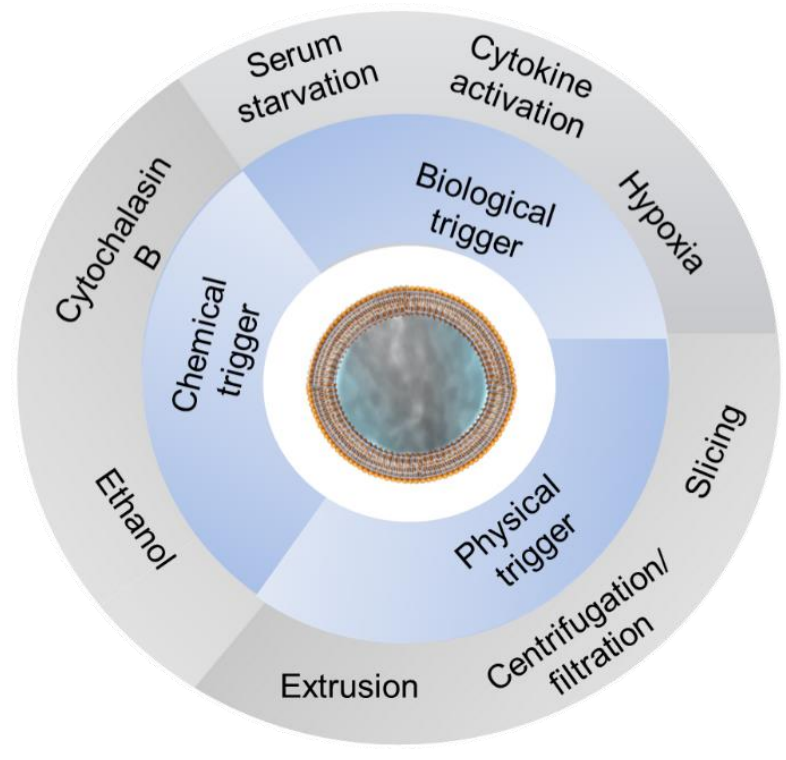

Figure 3: Biological, chemical and physical triggers able to stimulate or induce EV release by parent cells.

\section{EV loading technology}

EVs have been reported to be loaded with chemotherapeutic agents, nanoparticles, radiotracers, miRNA and fluorescent probes (Figure 4a). Loading step is a key process for EV-based therapy and imaging. In this regard, technical approaches devoted to cope with this matter can be classified in three categories. One of them relies on pre-loading parental cell with the cargo in question followed by inducing EV production. As such, the released EVs inherit not only cell features but also cytoplasmic solutes as well as the cargo. Other strategies are either based on loading the EVs during the process of formation using physical methods, or on directly loading the EVs after their production and isolation (Figure 4b-d). 

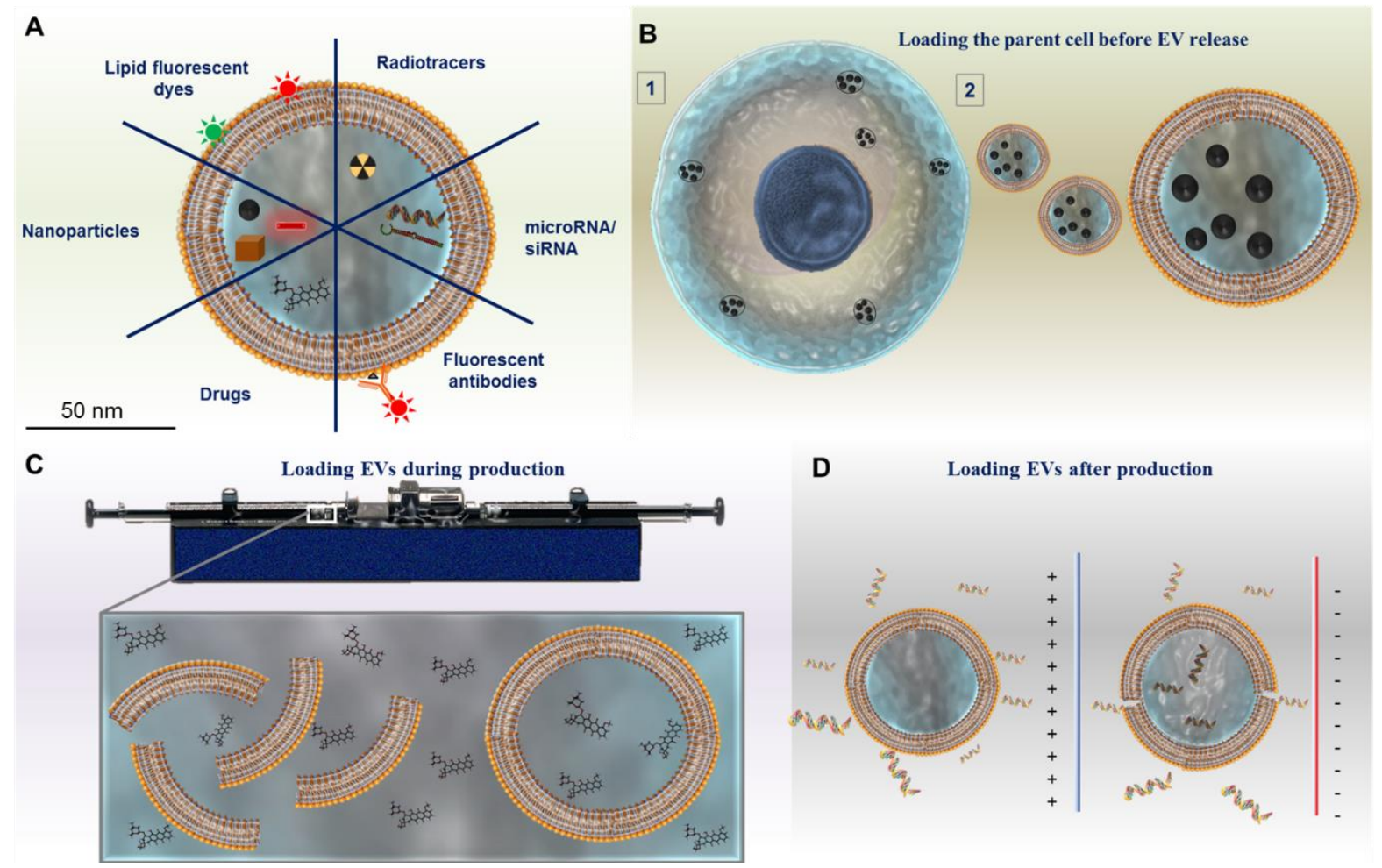

Figure 4: Engineering extracellular vesicles to enclose molecules, macromolecules or nanoparticles for therapy or imaging purposes (A). Loading strategies may rely on pre-loading parental cells with the cargo of interest before inducing EV release (B); loading the EVs during their production step (C) or directly loading EVs after their production and isolation (D).

\subsection{EV production form a previously loaded parent cell}

One of the main approaches for loading a compound of interest into EVs is the transfection of the donor cells in order to make them over-express a RNA or a protein that will then be packed into the exosome cytosol or its membrane. This technique has been used for the loading of miRNAs into EVs in few studies using miRNA expression vectors or pre-miRNAS [124, 125]. For example, Wiklander et al. transfected HEK293T cells with enhanced green fluorescent proteins (EGFP) plasmid using polyethylemine in order to produce EGFP-positive exosomes [126].

A similar approach has also been successfully used to produce EVs loaded with a particular protein. This is performed either modifying the protein sequence by adding a membrane targeting sequence (e.g. myristoylation domain, PIP3 doming, prenylation domain) [127] or by creating fusion proteins with natural 
EV targeted proteins such as lamp2b, PDGFR [128],C1-C2 domains of lacthaderin [129] or tetraspanins [101]. Álvarez-Erviti et al. have used this method to produce neuron targeting exosomes by fusing lamp2b protein to the brain targeting RVG peptide [101]. This very appealing publication led to further use of this technique by other groups [130]. However, Hung and Leonard recently demonstrated that peptides fused to $\mathrm{N}$ terminus of Lamp2b were probably degraded by endosomal proteases, resulting in no detection of the peptide on both cells and EVs [131]. Interestingly, glycosilation protected the peptide from degradation. Finally, this two-step procedure (engineering followed by loading) seems to be quite laborious and difficult to transfer into clinical practice, particularly if patient derived cells are used.

Another approach is loading donor cells with exogenous moleules/particles, which are then released into EVs. This is an approach that has been used by our group. Using a top-down procedure, we designed EVs loaded with nanoparticles from parent cells that had previously been loaded with the compound of interest. HUVEC cells were incubated with various nanoparticles to allow their internalization. Biological stress caused by serum starvation was used to trigger the release of vesicles that inherit the cargo from the parent cell. This strategy enabled the encapsulation into EVs of different nanoparticles, independently from their chemical composition or shape such as iron oxide nanocubes, gold nanoparticles, iron oxide nanoparticles, quantum dots and gold/iron oxide nanodimers [132]. The combined loading of drug and nanoparticles in EVs can also be done following this method. In another study carried out in our laboratory, vesicles derived from macrophages (THP-1) cells were successfully loaded with iron oxide nanoparticles and several therapeutic molecules irrespective of their molecular weight or their hydrophobicity [133]. Different magnetic vesicles loaded with either a chemotherapeutic drug (doxorubicin), an anticoagulant protein (tissue-plasminogen activator (t-PA)) or two photosensitizers (disulfonated tetraphenylchlorin (TPCS2a) [133] or mTHPC [134] were produced. However, these techniques are of low yield, limiting its application.

\subsection{Loading during EV production}

EVs can also be loaded during the process of production, in other words, they can encapsulate the desired cargo whilst being formed. This approach can only be used when EVs are formed using physically-triggered methods of fractionation of the plasma membrane and reformation of micro/nano-size vesicles.

An example is the study performed by Toledano et al. in which they report the drug loading of nanoghosts produced from the membrane of MSCs. The cells are treated with a tris-magnesium buffer which removes, in 
theory, a part of the cytosol. Cells are then processed by centrifugation, precipitation and washing steps to obtain "cytoplasm-free" cells (referred to as ghost-cells), which are then mildly sonicated to fractionate the membrane. It has to be noted that no proof of cytoplasm depletion is provided. The product is extruded $0.4 \mu \mathrm{m}$ polycarbonate membrane in presence of tumor-necrosis-factor related apoptosis inducing ligand (TRAIL). The final outcome are TRAIL-loaded nano-sized vesicles [135]. Similarly, the disruption of platelets by sonication in presence of nanoparticles was reported to result in nanoparticle encapsulation [136]. In another study, doxorubicin-loaded vesicles were designed by inducing the disruption of macrophages following serial extrusion steps using filters in a medium containing doxorubicin [116].

On overall, the disrupting/reformatting EV loading methods seem to be efficient for the loading of both lipophilic and hydrophilic compounds. However, this technique has some drawbacks: EV membrane disruption during the process probably leads to potential membrane asymmetry loss, loss of the inner physiological cargo of the EVs (miRNA, soluble proteins) and requires high volume/concentration of the hydrophilic or lipophilic compound to be loaded. The loss of membrane asymmetry may potentially impact EV fate considering that it can modify receptor presentation and consequently recognition by recipient cells.

\subsection{Loading after production}

Another option is loading EVs once they have already been produced. These approaches may be based on simple EV incubation with cargo or may rely on chemical transfection agents or physically-triggered strategies. Concerning the latter, low molecular weight and hydrophobic molecules can be directly loaded into EVs by simple incubation in a passive way. For instance, molecules such as curcumin have been efficiently loaded into exosomes after only 5 minutes of incubation [137]. Additionally, miRNAs [138] and therapeutic molecules such as doxorubicin [116] have also been loaded into exosomes by incubation at $37^{\circ} \mathrm{C}$ for 1 and 2 hours, respectively. Spontaneous EV loading has been also reported for lipophilic tracers such as PKH26 or PKH67, which can be transferred into EV membrane via hydrophobic interactions [40, 107]. However, lipidic tracer incorporation should be performed limiting molecule excess to prevent the formation of micelles that can be co-purified with the EVs, leading to contamination.

Chemical transfection approaches have also been reported to load siRNA in EVs, but the loading efficiency was low compared to other methods [139]. Additionally, leftover micelles formed from the transfection agents 
(e.g. Lipofectamine 2000) can be present in the resulting EV preparation. Overall, this method seems inadequate for therapeutic purposes, mainly due to the toxicity of cationic lipids.

Physically-triggered strategies comprising electroporation, sonication, freeze-thaw cycles or extrusion may be used for loading EVs after their production. Electroporation consists in submitting EVs, suspended in a solution containing the cargo of choice, to an electrical field. Pores are formed during this process into EV membrane, allowing the diffusion of the cargo, mostly siRNA, into the lumen of the exosomes [140]. Electroporation has been reported to obtain siRNA-loaded exosomes to knockdown a target protease in Alzheimer's disease [101]. Nevertheless, Kooijmans et al. reported later that the results from this study were indeed an artefact [141]. The process of electroporation induced electrochemical reactions, leading to the release from the electrode of metal ions, which induced siRNA aggregation. Such aggregates, co-precipitated with exosomes during the centrifugation step, mediated siRNA transfer and brain targeted gene silencing. Indeed, aggregation inhibition by a metal ion chelator such as EDTA prevented siRNA co-precipitation with exosomes. Additional methods of loading have been tested based on the incubation of EVs with the desired cargo or relying on sonication, freeze-thaw cycles or extrusion [142]. High-energy probe sonication was used to load MSC derived nanoghost with plasmic cDNA (pDNA). However, due to the high shear force applied during sonication, naked pDNA was fragmented. To solve this problem, polycations (e.g. polyethylenimine) were used to compress and protect the DNA from degradation [143]. For encapsulating catalase (a relatively high molecular weight antioxidant enzyme) into exosomes, sonication and extrusion method were the most efficient method, followed by the freeze-thaw cycle and simple incubation at room temperature. The formation of pores as well as the disruption and resealing of exosomes following sonication or extrusion enabled catalase diffusion into EVs [142].

Apart from engineering the internal vesicle cargo, the EV membrane may be also directly modified at will. Our group has also reported a method of direct vesicle "decoration" based on the use of nanoparticles. Endothelial cells were incubated with anion iron oxide nanoparticles that were capable of attaching to EV membrane by electrostatic interactions [144]. Other groups have also reported the use of antibodies to decorate EV surface in vivo. This is the case of platelet EVs reported to be labelled with fluorescent annexin and different antibodies by simple incubation (anti-CD63, anti-CD61 and anti-CD62P) [145]. Nevertheless, antibody dissociation from the exosome can occur when encountering other endogenous antigens. Click 
chemistry was also proposed to functionalize the EVs surface. Although chemical modification may partly changes the EV biological property, this method allows a rapid covalent bonding of specific chemical groups through a two-step process in presence of copper [146, 147]. First, an alkyne group is attached to the EV membrane proteins. Then, this chemical group is linked to an azyde-functionalized compound of interest. Grafting of fluorescent dye was achieved as a proof of concept.

A recently reported approach for loading EVs is forcing membrane fusion of EVs with synthetic liposomes loaded with the compound of interest by freeze-thaw cycles. Sato et al. used several freeze-thaw cycles to disrupt membranes by the growth of ice crystals leading to reformation of hybrid EV/liposomes while thawing. With this method, the properties of the exosome surface can easily be modified by fusing them with liposomes embedding peptides or antibodies of interest as well as poly(ethylene glycol) (PEG) [148]. Alternatively micelles composed of PEG lipids have been incorporated into EV membrane by co-incubation, resulting in an increase of the EV half-life in mice [149] and coupling of a targeting agent to EVs [150]. Another study from the same group described the use of GPI anchored proteins to decorate EVs with coupled nanobody, allowing targeting in vitro [151].

Overall, despite all the different loading methods described up to date, there is an urgent need for comparison of EV loading methods. Besides, EV integrity and loss of intrinsic material after the loading process also deserve further attention.

\section{Engineering EVs for therapy and physically-triggered therapy and theranosis}

Currently, clinically used drug delivery systems are mostly chemically synthesized based on lipids [152]. The emergence of naturally derived carriers featuring highly desired attributes is increasingly recognized [153]. EVs are one of the highlighting examples as they feature many advantages compared to already existing synthetic systems. In the first place, EVs can be obtained from the cells of patients in an autologous set-up, and thus they may be less immunogenic than artificial delivery vehicles. Secondly, they have phospholipid bilayer, which can fuse with the membrane of recipient cells, thus improve the cellular internalization of the encapsulated molecule [154]. Finally, the small size and the constitution of EVs partially protect EVs from phagocytosis by the mononuclear phagocyte system and promotes their extravasation through tumor vessels and their diffusion in tumor tissues [155]. Besides their intrinsic features, as explained throughout this review, EVs may be processed to display extrinsic contrast and therapeutic properties. 
Therapeutic properties have been evidenced for several drug-loaded EVs. For instance, the intranasal administration of curcumin-loaded exosomes protected mice from brain inflammation [137]. Curcumin-loaded exosomes are currently under clinical investigation as a potential colon cancer treatment (clinical trial no. NCT01294072). The exosomes used in this studies are from plant origin and are intended to be administered via the oral route to patients. The rationale behind the use of plant-derived exosomes is the possibility of producing large amounts of exosomes for carrying out therapeutic studies in a clinical setting [156].

Another therapeutic molecule that has been successfully encapsulated in EVs and showed promising results is doxorubicin [130]. The same compound was also encapsulated in another study but using RAW 264.7-derived exosomes and tested on an ectopic mouse colon adenocarcinoma model. In vivo experiments showed that tumor growth was substantially reduced and cardiac adverse effects drastically decreased that are normally observed when administering drug-loaded exosome in comparison to the free drug. In addition, a comparative study with commercial doxorubicin-loaded liposomes (Doxil) showed that doxorubicin-loaded exosomes reduced tumor growth more efficiently [116].

Besides exosomes, nanoghosts have been investigated as doxorubicin nanocarriers. In this approach, doxorubicin-loaded biodegradable PLGA nanoparticles were coated with monocyte-derived membranes leading to an increment in cellular uptake and cytotoxicity in MCF7 cells in vitro [157]. Nanoghosts have also been investigated as a drug delivery system in vivo. As an example, nanoghosts produced by decorating emtansine-loaded liposomes with macrophage membrane were found to augment drug circulation time, but also targeting of $4 \mathrm{~T} 1$ metastatic loci in lung. Such nanoghosts markedly reduced the number of metastasis nodules in lungs, displaying a 4 fold higher effect compared to drug-loaded liposomes [122].

Apart from therapeutic molecules, other studies have also investigated the delivery of interfering RNAs via EVs. Ohno et al. produced EVs containing let-7a miRNA for tumor suppression. Results showed that EVs were successfully taken up by malignant cells, inhibiting them [125]. Plasmid cDNA (pDNA) has also been successfully delivered into cancer cells by loading into MSC-derived nanoghosts. The pDNA, encoding for a cancer-toxic gene (C-terminal fragment of the human matrix metalloprotease-2), was transfected into cancer cells in both in vitro and in vivo models. Tumor growth was inhibited in a metastatic lung cancer and a subcutaneous prostate cancer model [150]. 
A pioneer study performed by our group reported the design of different physical-triggered hybrid endothelial cell-derived EVs containing heating nanoparticles, fluorescent quantum dots and/or contrast nanoparticle agents. These EVs delivered thermal therapy as they heated under the effect of an alternating magnetic field and tracking could be performed by fluorescent imaging or MRI [132]. In another of our studies we produced THP1 macrophage-derived EVs loaded with both drugs and nanoparticles. We showed that photosensitizerloaded magnetic EV internalization by malignant cells could be modulated in a spatio-temporal manner using magnetic forces. As a result, the death of tumor cells could be spatio-temporally controlled [133]. Such photosensitizer-loaded magnetic EVs were administered to tumor-bearing mice. We evidenced that they could be monitored by MRI and fluorescence imaging while eliciting a light-induced cytotoxic effect on malignant cells. Our group coined the term "theranosomes" for such physically-triggered EVs delivering a therapy and enabling imaging [134]. We have also demonstrated that cancer cells, treated with a cytotoxic drug and magnetic nanoparticles, released EVs that sequestrate this dual theranostic cargo being able to disseminate it. In vivo experiments showed that cancer EVs sequestrating a theranostic photosensitizer drug were detected in the blood following photodynamic therapy in tumor-bearing mice [158]. In an interesting approach, cancer EVs were investigated for malignancy-targeted delivery of theranostics by Bose and colleagues. Cancer theranostic EVs were prepared by loading with gold-iron oxide nanoparticles, indocyanine green and an antagomirs (blocking the oncogenic miR-21). The theranostic potential of these EVs was demonstrated in a murine model with a preferential tumor accumulation evidenced by optical imaging and MRI [159].

\section{Concluding remarks}

Personalized nanomedicine offers new prospects for individualized diagnosis profiles, stratification of patients and the tailoring of clinical treatments. For instance, by providing feedbacks on the accumulation of a theranostic agent in the target versus healthy tissues, nanomedicine may allow to discriminate patients who will probably respond positively to a specific treatment from those featuring an elevated risk to develop side effects, thus requiring a different therapeutic option [165]. EV-based personalized nanomedicine opens up additional possibilities in customizing therapy and diagnosis as EVs carry along disease hallmarks, intrinsic regenerative effectors, while also enabling the biocamouflage of theranostic agents.

Currently, EV diagnostic platforms are under development and clinical validation by companies such as Exosomics Siena and Exosome Sciences. Exosome Diagnostics and Caris Life Science are additional 
companies also focusing on harvesting and deciphering a multitude of molecular information enclosed in EVs to guide treatment decisions for personalized healthcare.

The clinical investigation of EV-based personalized therapy is in its beginning stages but it is increasingly expanding. Moving EV-based personalized therapy to the clinical practice will require focus on the development of cost-effective, standardized methods for EV production and loading in a scale-up perspective. Considering EV production and loading, a trade-off between vesicle yield, loading and the amount of operational steps should be considered. In this regard, physically triggered methods seem to be very promising to obtain high yield in EV production as well as high EV loading while requiring no further procedures to eliminate the vesiculation-triggering agent. However, the impact of mechanical stress on EV biological properties should be assessed before considering physical stress an eligible method. An additional point to be considered is EV precursor cell choice, as it directly impacts on EV yield and intrinsic EV properties such as therapeutic effect, half-life and biodistribution. Clinical translation demands compliance with regulatory requirements. In this regard, preclinical and clinical development of EVs should be guided by safety standards. Accordingly, aspects related to traceability, processing, transport and storage of EVs become essential issues to guarantee health protection of donors as well as recipients [160].

Until now, studies provided the basis for customizing EVs to deliver drugs, proteins, nanoparticles and nucleic acids. Proof-of-principle studies on physically-triggered EV theranostic bring new hopes for spatio-temporal controlled therapy combined to tracking. Future investigations should focus on establishing current good manufacturing practice (cGMP) methods for EV manufacturing, leading to standardization and increased regulatory confidence in EV products. cGMP EV production would be equally useful to produce EV standards for comparative purposes. This would markedly improve the uniformity, consistency, and reproducibility of EV quality control and characterization. Multi-technique EV profiling should be performed in order to determine EV size, polydispersity, purity, biochemical markers and sterility in batches. Storage protocols should be validated in order to ensure that EVs will keep their physico-chemical features and therapeutic properties during and after shelf time. Additionally, EV potency and toxicological issues should be accessed in vitro and in appropriate in vivo models. Issues related to the influence of the administration route on EV biodistribution and half-life should be considered as well as the frequency of administration to achieve a 
therapeutic effect. Future advances in EV processing taking into account these issues are expected to progress EV-based personalized medicine concept towards implementation into the clinical practice.

\section{Acknowledgements}

The authors acknowledge "Institut de Recherches Internationales SERVIER", ITMO-Inserm Plan Cancer 2014-2019, ITMO Cancer and Fondation ARC for funding and the doctoral school "Frontiers du vivant".

\section{References}

[1] B. Hugel, M.C. Martinez, C. Kunzelmann, J.M. Freyssinet, Membrane microparticles: two sides of the coin, Physiology (Bethesda, Md.), 20 (2005) 22-27.

[2] J. Ratajczak, M. Wysoczynski, F. Hayek, A. Janowska-Wieczorek, M.Z. Ratajczak, Membranederived microvesicles: important and underappreciated mediators of cell-to-cell communication, Leukemia, 20 (2006) 1487-1495.

[3] G. Camussi, M.C. Deregibus, S. Bruno, V. Cantaluppi, L. Biancone, Exosomes/microvesicles as a mechanism of cell-to-cell communication, Kidney international, 78 (2010) 838-848.

[4] J.J. Jimenez, W. Jy, L.M. Mauro, C. Soderland, L.L. Horstman, Y.S. Ahn, Endothelial cells release phenotypically and quantitatively distinct microparticles in activation and apoptosis, Thrombosis research, 109 (2003) 175-180.

[5] S.F. Mause, C. Weber, Microparticles: protagonists of a novel communication network for intercellular information exchange, Circulation research, 107 (2010) 1047-1057.

[6] G. Raposo, W. Stoorvogel, Extracellular vesicles: exosomes, microvesicles, and friends, The Journal of cell biology, 200 (2013) 373-383.

[7] L. Camacho, P. Guerrero, D. Marchetti, MicroRNA and protein profiling of brain metastasis competent cell-derived exosomes, PloS one, 8 (2013) e73790. 
[8] M.C. Boelens, T.J. Wu, B.Y. Nabet, B. Xu, Y. Qiu, T. Yoon, D.J. Azzam, C. Twyman-Saint Victor, B.Z. Wiemann, H. Ishwaran, P.J. Ter Brugge, J. Jonkers, J. Slingerland, A.J. Minn, Exosome transfer from stromal to breast cancer cells regulates therapy resistance pathways, Cell, 159 (2014) 499-513.

[9] P. Wolf, The nature and significance of platelet products in human plasma, British journal of haematology, 13 (1967) 269-288.

[10] M. Krause, A. Samoylenko, S.J. Vainio, Exosomes as renal inductive signals in health and disease, and their application as diagnostic markers and therapeutic agents, Frontiers in cell and developmental biology, 3 (2015) 65.

[11] A.P. Owens, 3rd, N. Mackman, Microparticles in hemostasis and thrombosis, Circulation research, 108 (2011) 1284-1297.

[12] B.S. Holder, C.L. Tower, C.J. Jones, J.D. Aplin, V.M. Abrahams, Heightened proinflammatory effect of preeclamptic placental microvesicles on peripheral blood immune cells in humans, Biology of reproduction, 86 (2012) 103.

[13] N. Cloutier, S. Tan, L.H. Boudreau, C. Cramb, R. Subbaiah, L. Lahey, A. Albert, R. Shnayder, R. Gobezie, P.A. Nigrovic, R.W. Farndale, W.H. Robinson, A. Brisson, D.M. Lee, E. Boilard, The exposure of autoantigens by microparticles underlies the formation of potent inflammatory components: the microparticle-associated immune complexes, EMBO molecular medicine, 5 (2013) 235-249.

[14] P.S. Prakash, C.C. Caldwell, A.B. Lentsch, T.A. Pritts, B.R. Robinson, Human microparticles generated during sepsis in patients with critical illness are neutrophil-derived and modulate the immune response, The journal of trauma and acute care surgery, 73 (2012) 401-406.

[15] R. Valenti, V. Huber, M. Iero, P. Filipazzi, G. Parmiani, L. Rivoltini, Tumor-released microvesicles as vehicles of immunosuppression, Cancer research, 67 (2007) 2912-2915. 
[16] K. Al-Nedawi, B. Meehan, J. Micallef, V. Lhotak, L. May, A. Guha, J. Rak, Intercellular transfer of the oncogenic receptor EGFRvIII by microvesicles derived from tumour cells, Nature cell biology, 10 (2008) 619-624.

[17] J. Skog, T. Wurdinger, S. van Rijn, D.H. Meijer, L. Gainche, M. Sena-Esteves, W.T. Curry, Jr., B.S. Carter, A.M. Krichevsky, X.O. Breakefield, Glioblastoma microvesicles transport RNA and proteins that promote tumour growth and provide diagnostic biomarkers, Nature cell biology, 10 (2008) 1470-1476.

[18] R.C. Lai, T.S. Chen, S.K. Lim, Mesenchymal stem cell exosome: a novel stem cell-based therapy for cardiovascular disease, Regenerative medicine, 6 (2011) 481-492.

[19] S. Bates, Progress towards personalized medicine, Drug Discovery Today, 15 (2010) 115-120. [20] A. Hubert, C. Subra, M.-A. Jenabian, P.-F. Tremblay Labrecque, C. Tremblay, B. Laffont, P. Provost, J.-P. Routy, C. Gilbert, Elevated Abundance, Size, and MicroRNA Content of Plasma Extracellular Vesicles in Viremic HIV-1+ Patients: Correlations With Known Markers of Disease Progression, Journal of Acquired Immune Deficiency Syndromes, 70 (2015) 219-227.

[21] D. Mege, L. Panicot-Dubois, M. Ouaissi, S. Robert, I. Sielezneff, B. Sastre, F. Dignat-George, C. Dubois, The origin and concentration of circulating microparticles differ according to cancer type and evolution: A prospective single-center study, International Journal of Cancer, 138 (2016) 939-948.

[22] B.K. Thakur, H. Zhang, A. Becker, I. Matei, Y. Huang, B. Costa-Silva, Y. Zheng, A. Hoshino, H. Brazier, J. Xiang, C. Williams, R. Rodriguez-Barrueco, J.M. Silva, W. Zhang, S. Hearn, O. Elemento, N. Paknejad, K. Manova-Todorova, K. Welte, J. Bromberg, H. Peinado, D. Lyden, Double-stranded DNA in exosomes: a novel biomarker in cancer detection, Cell Research, 24 (2014) 766-769.

[23] M.R. Speicher, K. Pantel, Tumor signatures in the blood, Nat Biotechnol, 32 (2014) 441-443. [24] I. Tatischeff, A. Alfsen, A new biological strategy for drug delivery: eucaryotic cell-derived nanovesicles, Journal of Biomaterials and Nanobiotechnology, 2 (2011) 494. 
[25] J.G. van den Boorn, M. Schlee, C. Coch, G. Hartmann, SiRNA delivery with exosome nanoparticles, Nat Biotechnol, 29 (2011) 325-326.

[26] B.T. Pan, R.M. Johnstone, Fate of the transferrin receptor during maturation of sheep reticulocytes in vitro: selective externalization of the receptor, Cell, 33 (1983) 967-978.

[27] Y. Lee, S. El Andaloussi, M.J. Wood, Exosomes and microvesicles: extracellular vesicles for genetic information transfer and gene therapy, Human molecular genetics, 21 (2012) R125-134. [28] J.C. Akers, D. Gonda, R. Kim, B.S. Carter, C.C. Chen, Biogenesis of extracellular vesicles (EV): exosomes, microvesicles, retrovirus-like vesicles, and apoptotic bodies, Journal of neurooncology, 113 (2013) 1-11.

[29] C. Thery, L. Zitvogel, S. Amigorena, Exosomes: composition, biogenesis and function, Nature reviews. Immunology, 2 (2002) 569-579.

[30] P.A. Leventis, S. Grinstein, The distribution and function of phosphatidylserine in cellular membranes, Annual review of biophysics, 39 (2010) 407-427.

[31] N. Arraud, R. Linares, S. Tan, C. Gounou, J.M. Pasquet, S. Mornet, A.R. Brisson, Extracellular vesicles from blood plasma: determination of their morphology, size, phenotype and concentration, J Thromb Haemost, 12 (2014) 614-627.

[32] S. Elmore, Apoptosis: a review of programmed cell death, Toxicologic pathology, 35 (2007) 495-516.

[33] E. van der Pol, A.N. Boing, P. Harrison, A. Sturk, R. Nieuwland, Classification, functions, and clinical relevance of extracellular vesicles, Pharmacological reviews, 64 (2012) 676-705.

[34] J. Ratajczak, K. Miekus, M. Kucia, J. Zhang, R. Reca, P. Dvorak, M.Z. Ratajczak, Embryonic stem cell-derived microvesicles reprogram hematopoietic progenitors: evidence for horizontal transfer of mRNA and protein delivery, Leukemia, 20 (2006) 847-856.

[35] G. Camussi, M.C. Deregibus, S. Bruno, C. Grange, V. Fonsato, C. Tetta, Exosome/microvesicle-mediated epigenetic reprogramming of cells, American journal of cancer research, 1 (2011) 98-110. 
[36] S. Gatti, S. Bruno, M.C. Deregibus, A. Sordi, V. Cantaluppi, C. Tetta, G. Camussi,

Microvesicles derived from human adult mesenchymal stem cells protect against ischaemiareperfusion-induced acute and chronic kidney injury, Nephrology, dialysis, transplantation : official publication of the European Dialysis and Transplant Association - European Renal Association, 26 (2011) 1474-1483.

[37] A. Bobrie, M. Colombo, G. Raposo, C. Thery, Exosome secretion: molecular mechanisms and roles in immune responses, Traffic (Copenhagen, Denmark), 12 (2011) 1659-1668.

[38] I. Del Conde, C.N. Shrimpton, P. Thiagarajan, J.A. Lopez, Tissue-factor-bearing microvesicles arise from lipid rafts and fuse with activated platelets to initiate coagulation, Blood, 106 (2005) 1604-1611.

[39] J. Rak, A. Guha, Extracellular vesicles--vehicles that spread cancer genes, BioEssays : news and reviews in molecular, cellular and developmental biology, 34 (2012) 489-497.

[40] H. Peinado, M. Aleckovic, S. Lavotshkin, I. Matei, B. Costa-Silva, G. Moreno-Bueno, M. Hergueta-Redondo, C. Williams, G. Garcia-Santos, C. Ghajar, A. Nitadori-Hoshino, C. Hoffman, K. Badal, B.A. Garcia, M.K. Callahan, J. Yuan, V.R. Martins, J. Skog, R.N. Kaplan, M.S. Brady, J.D. Wolchok, P.B. Chapman, Y. Kang, J. Bromberg, D. Lyden, Melanoma exosomes educate bone marrow progenitor cells toward a pro-metastatic phenotype through MET, Nature medicine, 18 (2012) 883-891.

[41] V. Dolo, S. D'Ascenzo, S. Violini, L. Pompucci, C. Festuccia, A. Ginestra, M.L. Vittorelli, S. Canevari, A. Pavan, Matrix-degrading proteinases are shed in membrane vesicles by ovarian cancer cells in vivo and in vitro, Clinical \& experimental metastasis, 17 (1999) 131-140.

[42] J.W. Kim, E. Wieckowski, D.D. Taylor, T.E. Reichert, S. Watkins, T.L. Whiteside, Fas ligand-positive membranous vesicles isolated from sera of patients with oral cancer induce apoptosis of activated T lymphocytes, Clinical Cancer Research, 11 (2005) 1010-1020.

[43] D.M. Pegtel, K. Cosmopoulos, D.A. Thorley-Lawson, M.A. van Eijndhoven, E.S. Hopmans, J.L. Lindenberg, T.D. de Gruijl, T. Wurdinger, J.M. Middeldorp, Functional delivery of viral 
miRNAs via exosomes, Proceedings of the National Academy of Sciences of the United States of America, 107 (2010) 6328-6333.

[44] B. Fevrier, D. Vilette, F. Archer, D. Loew, W. Faigle, M. Vidal, H. Laude, G. Raposo, Cells release prions in association with exosomes, Proceedings of the National Academy of Sciences of the United States of America, 101 (2004) 9683-9688.

[45] C. Quek, A.F. Hill, The role of extracellular vesicles in neurodegenerative diseases, Biochemical and biophysical research communications, (2016).

[46] S.A. Bellingham, B.B. Guo, B.M. Coleman, A.F. Hill, Exosomes: vehicles for the transfer of toxic proteins associated with neurodegenerative diseases?, Frontiers in physiology, 3 (2012) 124.

[47] N. Coltel, V. Combes, S.C. Wassmer, G. Chimini, G.E. Grau, Cell vesiculation and immunopathology: implications in cerebral malaria, Microbes and infection / Institut Pasteur, 8 (2006) 2305-2316.

[48] L.C. Azevedo, M.A. Pedro, F.R. Laurindo, Circulating microparticles as therapeutic targets in cardiovascular diseases, Recent patents on cardiovascular drug discovery, 2 (2007) 41-51.

[49] S. Wan, Z. Zhou, B. Duan, L. Morel, Direct B cell stimulation by dendritic cells in a mouse model of lupus, Arthritis and rheumatism, 58 (2008) 1741-1750.

[50] G. Muller, Microvesicles/exosomes as potential novel biomarkers of metabolic diseases,

Diabetes, metabolic syndrome and obesity : targets and therapy, 5 (2012) 247-282.

[51] A.J. Nauta, W.E. Fibbe, Immunomodulatory properties of mesenchymal stromal cells, Blood, 110 (2007) 3499-3506.

[52] N.K. Satija, V.K. Singh, Y.K. Verma, P. Gupta, S. Sharma, F. Afrin, M. Sharma, P. Sharma, R. Tripathi, G. Gurudutta, Mesenchymal stem cell-based therapy: a new paradigm in regenerative medicine, Journal of cellular and molecular medicine, 13 (2009) 4385-4402.

[53] M. Ratajczak, M. Kucia, T. Jadczyk, N. Greco, W. Wojakowski, M. Tendera, J. Ratajczak, Pivotal role of paracrine effects in stem cell therapies in regenerative medicine: can we translate 
stem cell-secreted paracrine factors and microvesicles into better therapeutic strategies\&quest, Leukemia, 26 (2011) 1166-1173.

[54] S. Gatti, S. Bruno, M.C. Deregibus, A. Sordi, V. Cantaluppi, C. Tetta, G. Camussi, Microvesicles derived from human adult mesenchymal stem cells protect against ischaemiareperfusion-induced acute and chronic kidney injury, Nephrology Dialysis Transplantation, (2011) $5,1474-83$.

[55] L.A. Reis, F.T. Borges, M.J. Simoes, A.A. Borges, R. Sinigaglia-Coimbra, N. Schor, Bone marrow-derived mesenchymal stem cells repaired but did not prevent gentamicin-induced acute kidney injury through paracrine effects in rats, PloS one, 7 (2012) e44092.

[56] Y. Zhou, H. Xu, W. Xu, B. Wang, H. Wu, Y. Tao, B. Zhang, M. Wang, F. Mao, Y. Yan, Exosomes released by human umbilical cord mesenchymal stem cells protect against cisplatininduced renal oxidative stress and apoptosis in vivo and in vitro, Stem Cell Research \& Therapy, 4 (2013) 34 .

[57] M. Herrera, V. Fonsato, S. Gatti, M. Deregibus, A. Sordi, D. Cantarella, R. Calogero, B. Bussolati, C. Tetta, G. Camussi, Human liver stem cell-derived microvesicles accelerate hepatic regeneration in hepatectomized rats, Journal of cellular and molecular medicine, 14 (2010) 16051618.

[58] T. Li, Y. Yan, B. Wang, H. Qian, X. Zhang, L. Shen, M. Wang, Y. Zhou, W. Zhu, W. Li, Exosomes derived from human umbilical cord mesenchymal stem cells alleviate liver fibrosis, Stem cells and development, 22 (2012) 845-854.

[59] C.Y. Tan, R.C. Lai, W. Wong, Y.Y. Dan, S.-K. Lim, H.K. Ho, Mesenchymal stem cell-derived exosomes promote hepatic regeneration in drug-induced liver injury models, Stem cell research \& therapy, 5 (2014) 76.

[60] L. Hu, J. Wang, X. Zhou, Z. Xiong, J. Zhao, R. Yu, F. Huang, H. Zhang, L. Chen, Exosomes derived from human adipose mensenchymal stem cells accelerates cutaneous wound healing via optimizing the characteristics of fibroblasts, Scientific Reports, 6 (2016) 32993. 
[61] J. Zhang, J. Guan, X. Niu, G. Hu, S. Guo, Q. Li, Z. Xie, C. Zhang, Y. Wang, Exosomes released from human induced pluripotent stem cells-derived MSCs facilitate cutaneous wound healing by promoting collagen synthesis and angiogenesis, Journal of Translational Medicine, 13 (2015) 49.

[62] T. Furuta, S. Miyaki, H. Ishitobi, T. Ogura, Y. Kato, N. Kamei, K. Miyado, Y. Higashi, M. Ochi, Mesenchymal Stem Cell-Derived Exosomes Promote Fracture Healing in a Mouse Model, Stem Cells Translational Medicine, 5 (2016) 1620-1630.

[63] S. Zhang, W. Chu, R. Lai, S. Lim, J. Hui, W. Toh, Exosomes derived from human embryonic mesenchymal stem cells promote osteochondral regeneration, Osteoarthritis and Cartilage, 24 (2016) 2135-2140.

[64] H. Xin, Y. Li, Y. Cui, J.J. Yang, Z.G. Zhang, M. Chopp, Systemic administration of exosomes released from mesenchymal stromal cells promote functional recovery and neurovascular plasticity after stroke in rats, Journal of Cerebral Blood Flow \& Metabolism, 33 (2013) 1711-1715.

[65] L. Alvarez-Erviti, Y. Seow, H. Yin, C. Betts, S. Lakhal, M.J. Wood, Delivery of siRNA to the mouse brain by systemic injection of targeted exosomes, Nat Biotech, 29 (2011) 341-345. [66] V.C. Ridger, C.M. Boulanger, A. Angelillo-Scherrer, L. Badimon, O. Blanc-Brude, M.-L. Bochaton-Piallat, E. Boilard, E.I. Buzas, A. Caporali, F. Dignat-George, Microvesicles in vascular homeostasis and diseases, Thrombosis and Haemostasis, 117 (2017) 1296-1316.

[67] A.-C. Vion, B. Ramkhelawon, X. Loyer, G. Chironi, C. Devue, G. Loirand, A. Tedgui, S. Lehoux, C.M. Boulanger, Shear stress regulates endothelial microparticle release, Circulation research, 112 (2013) 1323-1333.

[68] E. Hergenreider, S. Heydt, K. Tréguer, T. Boettger, A.J. Horrevoets, A.M. Zeiher, M.P. Scheffer, A.S. Frangakis, X. Yin, M. Mayr, Atheroprotective communication between endothelial cells and smooth muscle cells through miRNAs, Nature cell biology, 14 (2012) 249-256. 
[69] Y.-W. Chen, Y.-C. Chen, J.-S. Wang, Absolute hypoxic exercise training enhances in vitro thrombin generation by increasing procoagulant platelet-derived microparticles under high shear stress in sedentary men, Clinical Science, 124 (2013) 639-649.

[70] Y.-W. Chen, J.-K. Chen, J.-S. Wang, Strenuous exercise promotes shear-induced thrombin generation by increasing the shedding of procoagulant microparticles from platelets, Thrombosis and haemostasis, 103 (2010) 293-301.

[71] K.S. Sakariassen, P.A. Holme, U. Ørvim, R.M. Barstad, N.O. Solum, F.R. Brosstad, Shearinduced platelet activation and platelet microparticle formation in native human blood, Thrombosis research, 92 (1998) S33-S41.

[72] A. Piccin, W.G. Murphy, O.P. Smith, Circulating microparticles: pathophysiology and clinical implications, Blood reviews, 21 (2007) 157-171.

[73] C. Frühbeis, S. Helmig, S. Tug, P. Simon, E.-M. Krämer-Albers, Physical exercise induces rapid release of small extracellular vesicles into the circulation, Journal of extracellular vesicles, 4 (2015) 28239.

[74] N. Korin, M.J. Gounis, A.K. Wakhloo, D.E. Ingber, Targeted drug delivery to flow-obstructed blood vessels using mechanically activated nanotherapeutics, JAMA neurology, 72 (2015) 119-122. [75] J.M. Siegel, C.P. Markou, D.N. Ku, S. Hanson, A scaling law for wall shear rate through an arterial stenosis, Journal of biomechanical engineering, 116 (1994) 446-451.

[76] P. Diehl, F. Nagy, V. Sossong, T. Helbing, F. Beyersdorf, M. Olschewski, C. Bode, M. Moser, Increased levels of circulating microparticles in patients with severe aortic valve stenosis, Thrombosis and Haemostasis, 99 (2008) 711-719.

[77] N. Kuriyama, Y. Nagakane, A. Hosomi, T. Ohara, T. Kasai, S. Harada, K. Takeda, K. Yamada, K. Ozasa, T. Tokuda, Evaluation of factors associated with elevated levels of platelet-derived microparticles in the acute phase of cerebral infarction, Clinical and Applied Thrombosis/Hemostasis, 16 (2010) 26-32. 
[78] D. Bluestein, L. Niu, R.T. Schoephoerster, M.K. Dewanjee, Fluid mechanics of arterial stenosis: Relationship to the development of mural thrombus, Annals of Biomedical Engineering, 25 (1997) 344.

[79] V.V. McLaughlin, M.D. McGoon, Pulmonary arterial hypertension, Circulation, 114 (2006) 1417-1431.

[80] M. Gatzoulis, R. Alonso-Gonzalez, M. Beghetti, Pulmonary arterial hypertension in paediatric and adult patients with congenital heart disease, European Respiratory Review, 18 (2009) 154-161. [81] R.A. Preston, W. Jy, J.J. Jimenez, L.M. Mauro, L.L. Horstman, M. Valle, G. Aime, Y.S. Ahn, Effects of severe hypertension on endothelial and platelet microparticles, Hypertension, 41 (2003) 211-217.

[82] Y. Miyazaki, S. Nomura, T. Miyake, H. Kagawa, C. Kitada, H. Taniguchi, Y. Komiyama, Y. Fujimura, Y. Ikeda, S. Fukuhara, High shear stress can initiate both platelet aggregation and shedding of procoagulant containing microparticles, Blood, 88 (1996) 3456-3464.

[83] G. Chironi, A. Simon, B. Hugel, M. Del Pino, J. Gariepy, J.-M. Freyssinet, A. Tedgui, Circulating leukocyte-derived microparticles predict subclinical atherosclerosis burden in asymptomatic subjects, Arteriosclerosis, Thrombosis, and Vascular Biology, 26 (2006) 2775-2780. [84] C.M. Boulanger, N. Amabile, A. Tedgui, Circulating microparticles: a potential prognostic marker for atherosclerotic vascular disease, Hypertension, 48 (2006) 180-186.

[85] M. Staykova, D.P. Holmes, C. Read, H.A. Stone, Mechanics of surface area regulation in cells examined with confined lipid membranes, Proceedings of the National Academy of Sciences, 108 (2011) 9084-9088.

[86] J. Schmoranzer, G. Kreitzer, S.M. Simon, Migrating fibroblasts perform polarized, microtubule-dependent exocytosis towards the leading edge, Journal of Cell Science, 116 (2003) 4513-4519. 
[87] N.C. Gauthier, M.A. Fardin, P. Roca-Cusachs, M.P. Sheetz, Temporary increase in plasma membrane tension coordinates the activation of exocytosis and contraction during cell spreading, Proceedings of the National Academy of Sciences, 108 (2011) 14467-14472.

[88] N. Groulx, F. Boudreault, S.N. Orlov, R. Grygorczyk, Membrane reserves and hypotonic cell swelling, The Journal of Membrane Biology, 214 (2006) 43-56.

[89] E. Boucrot, T. Kirchhausen, Endosomal recycling controls plasma membrane area during mitosis, Proceedings of the National Academy of Sciences, 104 (2007) 7939-7944.

[90] N.C. Gauthier, O.M. Rossier, A. Mathur, J.C. Hone, M.P. Sheetz, Plasma membrane area increases with spread area by exocytosis of a GPI-anchored protein compartment, Molecular Biology of the Cell, 20 (2009) 3261-3272.

[91] A. Reddy, E.V. Caler, N.W. Andrews, Plasma Membrane Repair Is Mediated by Ca2+Regulated Exocytosis of Lysosomes, Cell, 106 (2001) 157-169.

[92] A. Savina, C.M. Fader, M.T. Damiani, M.I. Colombo, Rab11 promotes docking and fusion of multivesicular bodies in a calcium-dependent manner, Traffic (Copenhagen, Denmark), 6 (2005) 131-143.

[93] B. Hugel, M.C. Martínez, C. Kunzelmann, J.-M. Freyssinet, Membrane microparticles: two sides of the coin, Physiology, 20 (2005) 22-27.

[94] A.J. Jimenez, P. Maiuri, J. Lafaurie-Janvore, S. Divoux, M. Piel, F. Perez, ESCRT Machinery Is Required for Plasma Membrane Repair, Science, 343 (2014).

[95] J.F. Nabhan, R. Hu, R.S. Oh, S.N. Cohen, Q. Lu, Formation and release of arrestin domaincontaining protein 1-mediated microvesicles (ARMMs) at plasma membrane by recruitment of TSG101 protein, Proceedings of the National Academy of Sciences, 109 (2012) 4146-4151.

[96] H. Kalra, G. Drummen, S. Mathivanan, Focus on Extracellular Vesicles: Introducing the Next Small Big Thing, International Journal of Molecular Sciences, 17 (2016) 170. 
[97] W. Jo, D. Jeong, J. Kim, S. Cho, S.C. Jang, C. Han, J.Y. Kang, Y.S. Gho, J. Park, Microfluidic fabrication of cell-derived nanovesicles as endogenous RNA carriers, Lab on a chip, 14 (2014) 1261-1269.

[98] J.-Y. Zhu, D.-W. Zheng, M.-K. Zhang, W.-Y. Yu, W.-X. Qiu, J.-J. Hu, J. Feng, X.-Z. Zhang, Preferential Cancer Cell Self-Recognition and Tumor Self-Targeting by Coating Nanoparticles with Homotypic Cancer Cell Membranes, Nano Letters, 16 (2016) 5895-5901.

[99] R.W. Yeo, R.C. Lai, B. Zhang, S.S. Tan, Y. Yin, B.J. Teh, S.K. Lim, Mesenchymal stem cell: an efficient mass producer of exosomes for drug delivery, Advanced drug delivery reviews, 65 (2013) 336-341.

[100] A. Riches, E. Campbell, E. Borger, S. Powis, Regulation of exosome release from mammary epithelial and breast cancer cells - a new regulatory pathway, European journal of cancer (Oxford, England : 1990), 50 (2014) 1025-1034.

[101] L. Alvarez-Erviti, Y. Seow, H. Yin, C. Betts, S. Lakhal, M.J. Wood, Delivery of siRNA to the mouse brain by systemic injection of targeted exosomes, Nature biotechnology, 29 (2011) 341-345. [102] L. Kordelas, V. Rebmann, A.K. Ludwig, S. Radtke, J. Ruesing, T.R. Doeppner, M. Epple, P.A. Horn, D.W. Beelen, B. Giebel, MSC-derived exosomes: a novel tool to treat therapy-refractory graft-versus-host disease, Leukemia, 28 (2014) 970-973.

[103] W. Whitford, J.W. Ludlow, J.J. Cadwell, Continuous Production of Exosomes, Genetic Engineering \& Biotechnology News, 35 (2015) DOI: 10.1089/gen.1035.1016.1015.

[104] D.C. Watson, D. Bayik, A. Srivatsan, C. Bergamaschi, A. Valentin, G. Niu, J. Bear, M. Monninger, M. Sun, A. Morales-Kastresana, J.C. Jones, B.K. Felber, X. Chen, I. Gursel, G.N. Pavlakis, Efficient production and enhanced tumor delivery of engineered extracellular vesicles, Biomaterials, 105 (2016) 195-205.

[105] L. Sun, H.X. Wang, X.J. Zhu, P.H. Wu, W.Q. Chen, P. Zou, Q.B. Li, Z.C. Chen, Serum deprivation elevates the levels of microvesicles with different size distributions and selectively 
enriched proteins in human myeloma cells in vitro, Acta pharmacologica Sinica, 35 (2014) 381393.

[106] M. Wysoczynski, M.Z. Ratajczak, Lung cancer secreted microvesicles: underappreciated modulators of microenvironment in expanding tumors, International journal of cancer. Journal international du cancer, 125 (2009) 1595-1603.

[107] H.W. King, M.Z. Michael, J.M. Gleadle, Hypoxic enhancement of exosome release by breast cancer cells, BMC Cancer, 12 (2012) 421.

[108] S.E. Headland, H.R. Jones, A.S.V. D'Sa, M. Perretti, L.V. Norling, Cutting-Edge Analysis of Extracellular Microparticles using ImageStreamX Imaging Flow Cytometry, Scientific Reports, 4 (2014) 5237.

[109] H. Pick, E.L. Schmid, A.P. Tairi, E. Ilegems, R. Hovius, H. Vogel, Investigating cellular signaling reactions in single attoliter vesicles, Journal of the American Chemical Society, 127 (2005) 2908-2912.

[110] Z. Mao, R. Cartier, A. Hohl, M. Farinacci, A. Dorhoi, T.L. Nguyen, P. Mulvaney, J. Ralston, S.H. Kaufmann, H. Mohwald, D. Wang, Cells as factories for humanized encapsulation, Nano Lett, 11 (2011) 2152-2156.

[111] F. Momen-Heravi, S. Bala, K. Kodys, G. Szabo, Exosomes derived from alcohol-treated hepatocytes horizontally transfer liver specific miRNA-122 and sensitize monocytes to LPS, Sci Rep, 5 (2015) 9991.

[112] J. Jiang, D.S. Woulfe, E.T. Papoutsakis, Shear enhances thrombopoiesis and formation of microparticles that induce megakaryocytic differentiation of stem cells, Blood, 124 (2014) 20942103.

[113] M. Piffoux, A.K. Silva, J.B. Lugagne, P. Hersen, C. Wilhelm, F. Gazeau, Extracellular Vesicle Production Loaded with Nanoparticles and Drugs in a Trade-off between Loading, Yield and Purity: Towards a Personalized Drug Delivery System, Advanced Biosystems, 1 (2017) DOI: 10.1002/adbi.201700044. 
[114] J. Yoon, W. Jo, D. Jeong, J. Kim, H. Jeong, J. Park, Generation of nanovesicles with sliced cellular membrane fragments for exogenous material delivery, Biomaterials, 59 (2015) 12-20. [115] W. Jo, J. Kim, J. Yoon, D. Jeong, S. Cho, H. Jeong, Y.J. Yoon, S.C. Kim, Y.S. Gho, J. Park, Large-scale generation of cell-derived nanovesicles, Nanoscale, 6 (2014) 12056-12064.

[116] S.C. Jang, O.Y. Kim, C.M. Yoon, D.-S. Choi, T.-Y. Roh, J. Park, J. Nilsson, J. Lötvall, Y.-K. Kim, Y.S. Gho, Bioinspired exosome-mimetic nanovesicles for targeted delivery of chemotherapeutics to malignant tumors, ACS nano, 7 (2013) 7698-7710.

[117] J. Gao, S. Wang, Z. Wang, High yield, scalable and remotely drug-loaded neutrophil-derived extracellular vesicles (EVs) for anti-inflammation therapy, Biomaterials, 135 (2017) 62-73.

[118] C.-M.J. Hu, L. Zhang, S. Aryal, C. Cheung, R.H. Fang, L. Zhang, Erythrocyte membranecamouflaged polymeric nanoparticles as a biomimetic delivery platform, Proceedings of the National Academy of Sciences, 108 (2011) 10980-10985.

[119] W. Gao, C.M.J. Hu, R.H. Fang, B.T. Luk, J. Su, L. Zhang, Surface functionalization of gold nanoparticles with red blood cell membranes, Advanced Materials, 25 (2013) 3549-3553.

[120] R.A. Meyer, J.C. Sunshine, J.J. Green, Biomimetic particles as therapeutics, Trends in biotechnology, 33 (2015) 514-524.

[121] N.E. Toledano Furman, Y. Lupu-Haber, T. Bronshtein, L. Kaneti, N. Letko, E. Weinstein, L. Baruch, M. Machluf, Reconstructed Stem Cell Nanoghosts: A Natural Tumor Targeting Platform, Nano Letters, 13 (2013) 3248-3255.

[122] H. Cao, Z. Dan, X. He, Z. Zhang, H. Yu, Q. Yin, Y. Li, Liposomes Coated with Isolated Macrophage Membrane Can Target Lung Metastasis of Breast Cancer, ACS Nano, 10 (2016) 77387748.

[123] J. Gao, D. Chu, Z. Wang, Cell membrane-formed nanovesicles for disease-targeted delivery, Journal of Controlled Release, 224 (2016) 208-216. 
[124] M. Katakowski, B. Buller, X. Zheng, Y. Lu, T. Rogers, O. Osobamiro, W. Shu, F. Jiang, M. Chopp, Exosomes from marrow stromal cells expressing miR-146b inhibit glioma growth, Cancer letters, 335 (2013) 201-204.

[125] S.-i. Ohno, M. Takanashi, K. Sudo, S. Ueda, A. Ishikawa, N. Matsuyama, K. Fujita, T.

Mizutani, T. Ohgi, T. Ochiya, Systemically injected exosomes targeted to EGFR deliver antitumor microRNA to breast cancer cells, Molecular Therapy, 21 (2013) 185-191.

[126] O.P. Wiklander, J.Z. Nordin, A. O'Loughlin, Y. Gustafsson, G. Corso, I. Mager, P. Vader, Y.

Lee, H. Sork, Y. Seow, N. Heldring, L. Alvarez-Erviti, C.I. Smith, K. Le Blanc, P. Macchiarini, P. Jungebluth, M.J. Wood, S.E. Andaloussi, Extracellular vesicle in vivo biodistribution is determined by cell source, route of administration and targeting, Journal of extracellular vesicles, 4 (2015) 26316.

[127] B. Shen, N. Wu, J.-M. Yang, S.J. Gould, Protein targeting to exosomes/microvesicles by plasma membrane anchors, Journal of Biological Chemistry, 286 (2011) 14383-14395.

[128] S. Ohno, M. Takanashi, K. Sudo, S. Ueda, A. Ishikawa, N. Matsuyama, K. Fujita, T. Mizutani, T. Ohgi, T. Ochiya, N. Gotoh, M. Kuroda, Systemically injected exosomes targeted to EGFR deliver antitumor microRNA to breast cancer cells, Molecular therapy : the journal of the American Society of Gene Therapy, 21 (2013) 185-191.

[129] I.S. Zeelenberg, M. Ostrowski, S. Krumeich, A. Bobrie, C. Jancic, A. Boissonnas, A. Delcayre, J.B. Le Pecq, B. Combadiere, S. Amigorena, C. Thery, Targeting tumor antigens to secreted membrane vesicles in vivo induces efficient antitumor immune responses, Cancer research, 68 (2008) 1228-1235.

[130] Y. Tian, S. Li, J. Song, T. Ji, M. Zhu, G.J. Anderson, J. Wei, G. Nie, A doxorubicin delivery platform using engineered natural membrane vesicle exosomes for targeted tumor therapy, Biomaterials, 35 (2014) 2383-2390.

[131] M.E. Hung, J.N. Leonard, Stabilization of exosome-targeting peptides via engineered glycosylation, The Journal of biological chemistry, 290 (2015) 8166-8172. 
[132] A.K. Silva, R. Di Corato, T. Pellegrino, S. Chat, G. Pugliese, N. Luciani, F. Gazeau, C.

Wilhelm, Cell-derived vesicles as a bioplatform for the encapsulation of theranostic nanomaterials, Nanoscale, 5 (2013) 11374-11384.

[133] A.K. Silva, N. Luciani, F. Gazeau, K. Aubertin, S. Bonneau, C. Chauvierre, D. Letourneur, C. Wilhelm, Combining magnetic nanoparticles with cell derived microvesicles for drug loading and targeting, Nanomedicine: Nanotechnology, Biology and Medicine, 11 (2015) 645-655.

[134] A.K. Silva, J. Kolosnjaj-Tabi, S. Bonneau, I. Marangon, N. Boggetto, K. Aubertin, O.

Clement, M.F. Bureau, N. Luciani, F. Gazeau, C. Wilhelm, Magnetic and photoresponsive theranosomes: translating cell-released vesicles into smart nanovectors for cancer therapy, ACS Nano, 7 (2013) 4954-4966.

[135] N.E. Toledano Furman, Y. Lupu-Haber, T. Bronshtein, L. Kaneti, N. Letko, E. Weinstein, L. Baruch, M. Machluf, Reconstructed stem cell nanoghosts: a natural tumor targeting platform, Nano letters, 13 (2013) 3248-3255.

[136] C.M. Hu, R.H. Fang, K.C. Wang, B.T. Luk, S. Thamphiwatana, D. Dehaini, P. Nguyen, P. Angsantikul, C.H. Wen, A.V. Kroll, C. Carpenter, M. Ramesh, V. Qu, S.H. Patel, J. Zhu, W. Shi, F.M. Hofman, T.C. Chen, W. Gao, K. Zhang, S. Chien, L. Zhang, Nanoparticle biointerfacing by platelet membrane cloaking, Nature, 526 (2015) 118-121.

[137] X. Zhuang, X. Xiang, W. Grizzle, D. Sun, S. Zhang, R.C. Axtell, S. Ju, J. Mu, L. Zhang, L. Steinman, D. Miller, H.-G. Zhang, Treatment of Brain Inflammatory Diseases by Delivering Exosome Encapsulated Anti-inflammatory Drugs From the Nasal Region to the Brain, Molecular therapy : the journal of the American Society of Gene Therapy, 19 (2011) 1769-1779.

[138] K. Bryniarski, W. Ptak, A. Jayakumar, K. Püllmann, M.J. Caplan, A. Chairoungdua, J. Lu, B.D. Adams, E. Sikora, K. Nazimek, Antigen-specific, antibody-coated, exosome-like nanovesicles deliver suppressor T-cell microRNA-150 to effector T cells to inhibit contact sensitivity, Journal of Allergy and Clinical Immunology, 132 (2013) 170-181. e179. 
[139] T.A. Shtam, R.A. Kovalev, E.Y. Varfolomeeva, E.M. Makarov, Y.V. Kil, M.V. Filatov, Exosomes are natural carriers of exogenous siRNA to human cells in vitro, Cell Commun Signal, $11(2013) 1186$.

[140] E. Neumann, M. Schaefer-Ridder, Y. Wang, P.H. Hofschneider, Gene transfer into mouse lyoma cells by electroporation in high electric fields, The EMBO Journal, 1 (1982) 841-845. [141] S.A. Kooijmans, S. Stremersch, K. Braeckmans, S.C. de Smedt, A. Hendrix, M.J. Wood, R.M. Schiffelers, K. Raemdonck, P. Vader, Electroporation-induced siRNA precipitation obscures the efficiency of siRNA loading into extracellular vesicles, Journal of controlled release : official journal of the Controlled Release Society, 172 (2013) 229-238.

[142] M.J. Haney, N.L. Klyachko, Y. Zhao, R. Gupta, E.G. Plotnikova, Z. He, T. Patel, A. Piroyan, M. Sokolsky, A.V. Kabanov, Exosomes as drug delivery vehicles for Parkinson's disease therapy, Journal of Controlled Release, 207 (2015) 18-30.

[143] L. Kaneti, T. Bronshtein, D.N. Malkah, I. Kovregina, K.N. Letko, Y. Lupu-Haber, M. Fliman, B. Schoen, G. Kaneti, M. Machluf, Nanoghosts as a Novel Natural Nonviral Gene Delivery Platform Safely Targeting Multiple Cancers, Nano letters, 16 (2016) 1574.

[144] N. Vats, C. Wilhelm, P.E. Rautou, M. Poirier-Quinot, C. Pechoux, C. Devue, C.M.

Boulanger, F. Gazeau, Magnetic tagging of cell-derived microparticles: new prospects for imaging and manipulation of these mediators of biological information, Nanomedicine (London, England), 5 (2010) 727-738.

[145] A. Rank, R. Nieuwland, A. Crispin, S. Grutzner, M. Iberer, B. Toth, R. Pihusch, Clearance of platelet microparticles in vivo, Platelets, 22 (2011) 111-116.

[146] T. Smyth, K. Petrova, N.M. Payton, I. Persaud, J.S. Redzic, M.W. Graner, P. Smith-Jones, T.J. Anchordoquy, Surface functionalization of exosomes using click chemistry, Bioconjugate chemistry, 25 (2014) 1777-1784. 
[147] M. Wang, S. Altinoglu, Y.S. Takeda, Q. Xu, Integrating Protein Engineering and

Bioorthogonal Click Conjugation for Extracellular Vesicle Modulation and Intracellular Delivery, PloS one, 10 (2015) e0141860.

[148] Y.T. Sato, K. Umezaki, S. Sawada, S.A. Mukai, Y. Sasaki, N. Harada, H. Shiku, K. Akiyoshi, Engineering hybrid exosomes by membrane fusion with liposomes, Sci Rep, 6 (2016) 21933. [149] S. Kooijmans, L. Fliervoet, R. Van Der Meel, M. Fens, H. Heijnen, P.v.B. en Henegouwen, P. Vader, R. Schiffelers, PEGylated and targeted extracellular vesicles display enhanced cell specificity and circulation time, Journal of Controlled Release, 224 (2016) 77-85.

[150] S. Kooijmans, J. Gitz-Francois, R.M. Schiffelers, P. Vader, Recombinant phosphatidylserinebinding nanobodies for targeting of extracellular vesicles to tumor cells: a plug-and-play approach, Nanoscale 10(2018) 2413-2426.

[151] S.A. Kooijmans, C.G. Aleza, S.R. Roffler, W.W. van Solinge, P. Vader, R.M. Schiffelers, Display of GPI-anchored anti-EGFR nanobodies on extracellular vesicles promotes tumour cell targeting, Journal of extracellular vesicles, 5 (2016) 31053.

[152] R. Wang, P.S. Billone, W.M. Mullett, Nanomedicine in action: an overview of cancer nanomedicine on the market and in clinical trials, Journal of Nanomaterials, 2013 (2013) 1. [153] J.W. Yoo, D.J. Irvine, D.E. Discher, S. Mitragotri, Bio-inspired, bioengineered and biomimetic drug delivery carriers, Nature reviews. Drug discovery, 10 (2011) 521-535.

[154] I. Tatischeff, A. Annette, A new biological strategy for drug delivery: eucaryotic cell-derived nanovesicles., J Biomater Nanobiotechnol, 2 (2011) 494-499.

[155] J.G. van den Boorn, M. Schlee, C. Coch, G. Hartmann, SiRNA delivery with exosome nanoparticles., Nat Biotechnol, 29 (2011) 325-326.

[156] E.V. Batrakova, M.S. Kim, Using exosomes, naturally-equipped nanocarriers, for drug delivery, Journal of controlled release : official journal of the Controlled Release Society, 219 (2015) 396-405. 
[157] S. Krishnamurthy, M. Gnanasammandhan, C. Xie, K. Huang, M. Cui, J. Chan, Monocyte cell membrane-derived nanoghosts for targeted cancer therapy, Nanoscale, 8 (2016) 6981-6985.

[158] K. Aubertin, A.K. Silva, N. Luciani, A. Espinosa, A. Djemat, D. Charue, F. Gallet, O. BlancBrude, C. Wilhelm, Massive release of extracellular vesicles from cancer cells after photodynamic treatment or chemotherapy, Scientific Reports, 6 (2016) 35376.

[159] R. JC Bose, S. Uday Kumar, Y. Zeng, R. Afjei, E. Robinson, K. Lau, A. Bermudez, F. Habte, S.J. Pitteri, R. Sinclair, Tumor Cell-Derived Extracellular Vesicle-Coated Nanocarriers: An Efficient Theranostic Platform for Cancer-Specific Delivery of AntimiR-21 and Imaging Agents, ACS nano, 12 (2018) 10817-10832.

[160] T. Lener, M. Gimona, L. Aigner, V. Börger, E. Buzas, G. Camussi, N. Chaput, D. Chatterjee, F.A. Court, H.A. del Portillo, Applying extracellular vesicles based therapeutics in clinical trials-an ISEV position paper, Journal of extracellular vesicles, 4 (2015) 31; 30087. 